\title{
NUEVOS ENFOQUES DE LA INDEPENDENCIA JUDICIAL. DOS PUNTAS DE ICEBERG EN LA REFORMA DE LA LEY ORGÁNICA DEL PODER JUDICIAL: LA COMISIÓN PERMANENTE DEL CGPJ Y EL GABINETE TÉCNICO DEL TRIBUNAL SUPREMO
}

\author{
ROSA M. ${ }^{\mathrm{a}}$ FERNÁNDEZ RIVEIRA \\ Profesor Titular $(A)$ de Derecho Constitucional \\ Universidad Complutense de Madrid
}

\begin{abstract}
SUMARIO
I. Introducción. II. La reforma de la Ley Orgánica del Poder Judicial de 2015: la Comisión Permanente del CGPJ. III. El nuevo gabinete técnico al servicio del Tribunal Supremo. IV. Reflexiones sobre la parte sumergida ¿un renovado enfoque de la independencia judicial? V. Algunas conclusiones.
\end{abstract}

\section{INTRODUCCIÓN ${ }^{1}$}

Hace ya varios años publiqué un primer artículo sobre la reforma del Consejo General del Poder Judicial (LO 4/2013, de 28 de junio) que reflexionaba sobre sus puntos centrales en un pretendido marco de «regeneración democrática». En esos términos se refería el entonces Ministro de Justicia que la lideró, al explicar los propósitos auspiciados por su articulado ${ }^{2}$.

Hemos querido utilizar esta imagen gráfica del iceberg para presentar nuestras reflexiones. La ley orgánica del Poder Judicial de 1985, que atesora en sus

1 El presente trabajo es una primera parte de la investigación abierta sobre independencia judicial. El proyecto ha sido becado por el Ministerio de Educación Cultura y Deporte en el programa de estancias de investigación Salvador de Madariaga 2016 para completar en la Universidad Queen Mary de Londres.

2 DSCD, Pleno y Diputación Permanente, 18 de abril de 2013, n. ${ }^{\circ} 106$, pp. 16 y ss.: «... No podemos seguir con la imagen de politización de la justicia en España. No podemos seguir con una imagen en la que la división de poderes que consagra nuestra Constitución está, a efectos del ciudadano, absolutamente vulnerada como consecuencia de la extensión de la lucha partidista en la configuración de los órganos de gobierno de uno de los poderes del Estado» 
artículos más de una treintena de reformas, experimenta en octubre de 2015 , entre otros cambios, la modificación de la Comisión Permanente del CGPJ y un nuevo diseño del Gabinete Técnico como órgano de apoyo y asesoramiento del Tribunal Supremo.

Se reformaban en 2013 importantes aspectos del Consejo: sus competencias, su estructura en Comisiones, la designación de sus vocales, el nuevo régimen de dedicación al cargo, la forma de adopción de acuerdos, la eliminación de la obligación de comparecer de los vocales en sede parlamentaria o el propio proceso de renovación. Cambios como para rediseñar un órgano constitucional que siempre ha estado a la búsqueda de un modelo ${ }^{3}$. La mayoría de ellos hoy aguardan un fallo del Tribunal Constitucional que, el 5 de noviembre de 2013, admitía a trámite un recurso de inconstitucionalidad para analizarlos.

Desde entonces, el Consejo General del Poder Judicial del VII mandato ha aplicado la reforma 2013 y ha encarado una nueva en 2015. Un modelo claramente personalista en la figura de su Presidente y en el enorme peso otorgado a la Comisión Permanente, medidas que preocupan y que están decepcionando a casi todos ${ }^{4}$.

Las competencias del Consejo como órgano de gobierno de jueces y magistrados, que el Constituyente reflejó en el artículo 122, le han colocado a lo largo de los años como sujeto bisagra entre el ejecutivo y el judicial ${ }^{5}$. Un engranaje perverso que ha propiciado una articulación de legitimidades rocambolesca.

Las decisiones del Consejo (desde la comisión permanente) tras la reforma de 2013 y, según el artículo 638.2 de la LOPJ, pondrán fin a la vía administrativa y serán recurribles ante la sala de lo contencioso-administrativo del Tribunal Su-

3 FERnÁndez Riveira Rosa M. ${ }^{a}$, « ¿Regeneración Democrática? Algunas reflexiones sobre la nueva Ley Orgánica 4/2013, de 28 de junio, de reforma del Consejo General del Poder Judicial», en Revista de Derecho Político, número 91, septiembre-diciembre 2014, pp. 137-182; Gerpe Landín M. y Cabellos EspieRREz M.A., «La reforma permanente: el Consejo General del Poder Judicial a la búsqueda de un modelo», Revista Española de Derecho Constitucional, n. ${ }^{\circ}$ 103, enero-abril, CEPC, Madrid 2015, pp. 13 a 44.

4 El 21 de julio de 2015 se emite un comunicado conjunto por las Asociaciones de jueces, Francisco de Vitoria, Jueces para la Democracia y Foro Judicial independiente sobre la actuación del Presidente del CGPJ: «...la nefasta reforma de la LOPJ ha motivado que el cargo, en lugar de ser un «primus inter pares» como en otros Consejos, haya convertido a su Presidente en un instrumento de poder en el Palacio de la Ensenada que hace y deshace prácticamente a su antojo decidiendo incluso cuándo, cómo y dónde se cumple la LOPJ en cuanto a la renovación de las cuatro comisiones legales del CGPJ...».

5 El ejemplo inglés es muy ilustrativo en órganos bisagra entre poder judicial y ejecutivo «The role of the Lord Chancellor as a constitutional mechanism, through which the judiciary and executive communicate, raises a number of important issues. First, it suggests that the effectiveness of communications depends largely upon the individual Lord Chancellor, his ability to represents both sides and his standing with the judiciary and with his political colleagues. Secondly, it gives the Lord Chancellor considerable power. He can set the agenda and, should he so wish, play one side off against the other for his own ends. Thirdly, and most important, because of the secrecy endemic in the process, it may create suspicions of judicial/executive collusion, thereby undercoming judicial independence, which is better served by conversations between the executive and the judiciary being in the public domain rather than behind closed doors...». WoodHouse D., «The Office of Lord Chancellor», Oxford USA 2001, pp. 21 y ss. 
premo, en concreto por una sección integrada por el Presidente de la sala tercera y por los demás Presidentes de las siete secciones que la integran. Pero, ¿quién nombra al presidente del supremo que, en el modelo español lo es a su vez del Consejo? Según nuestra Ley orgánica, será el Pleno por mayoría de tres quintos en primera votación o, por mayoría simple en segunda, de entre los dos candidatos más votados (art. 586.3 LOPJ). Y no olvidamos que también el Pleno del Consejo nombra a todos aquellos cargos que impliquen discrecionalidad o apreciación de méritos (art. 599.4..$^{\circ}$ LOPJ), entre los que podemos incluir a los Magistrados del Tribunal Supremo. Un hilo conductor de legitimidades preocupante que va y viene del Consejo al Supremo, y que teje entre nombramientos y competencias una sutil tela de araña

Queda pendiente ubicar al legislativo en este juego de tronos, pero en el año 1986 el Tribunal Constitucional pronunció la sentencia (STC 108/1986, de 29 de julio) decisiva a estos efectos y así señaló en su fundamento jurídico décimo la principal justificación de la participación de las Cámaras en la designación de los vocales: «....asegurar que la composición del Consejo refleje el pluralismo existente en el seno de la sociedad y, muy en especial, en el seno del Poder Judicial. [...] Ciertamente, se corre el riesgo de frustrar la finalidad señalada de la Norma constitucional si las Cámaras, a la hora de efectuar sus propuestas, olvidan el objetivo perseguido y, actuando con criterios admisibles en otros terrenos, pero no en éste, atienden sólo a la división de fuerzas existente en su propio seno y distribuyen los puestos a cubrir entre los distintos partidos, en proporción a la fuerza parlamentaria de éstos».

Ahora bien, tal y como señalan algunos autores la sospecha es ya clara realidad: la incidencia de las cámaras legislativas en el consejo le convierte en vehículo de la voluntad partidista y así los jueces con mayor mérito, capacidad y contactos «políticos» situados en puestos de nombramientos discrecionales son la cúpula del poder judicial ${ }^{6}$.

El gobierno de los jueces y magistrados sigue sin propiciar la independencia judicial para la que fue diseñado, los pasos dados tras la reforma de 2013 así lo ponen de manifiesto. La más que «dudosa» forma de no renovación de la Comisión permanente un año después de su creación y la reforma de 2015, que dibuja un nuevo Gabinete Técnico asesorando al TS hablan por sí mismos.

La Ley Orgánica 7/2015, de 21 de julio ${ }^{7}$, modifica otra vez la Ley orgánica del Poder Judicial de 1985 afectando sus competencias y funcionamiento.

6 Ver, IÑiguez Hernández, D., El fracaso del autogobierno judicial, Civitas/Thomson, Madrid 2008; Griffith, J. A. G., The Politics of the Judiciary, (Fourth edition), London 1991; Gómez Fernández I., «Nombrar como manifestación del poder del Consejo: discrecionalidad e independencia del juez» en Independencia Judicial y Estado constitucional. El gobierno judicial. AGUIAR DE LuQUE (editor), Tirant monografías 988 , pp. 98 y ss.

7 Ley Orgánica 7/2015, de 21 de julio, por la que se modifica la Ley Orgánica del Poder Judicial 6/1985, de 1 de julio del Poder Judicial, BOE n. ${ }^{\circ}$ 174, miércoles 22 de julio de 2015, pp. 61593-61660. 
Como ya hemos anunciado, el apartado VIII de la exposición de motivos refiere dos de los aspectos reformados y que analizaremos en las siguientes páginas. Por un lado, se aumenta el número de miembros de la Comisión Permanente que pasan de cinco a siete, y así lo razona el legislador: «...las importantes atribuciones que tiene encomendadas deben ser ejercidas con plena dedicación por un número importante de vocales».

Por otro lado, se introduce una regulación más detallada del Gabinete técnico del Tribunal Supremo como órgano de asistencia a la Presidencia y a sus diferentes salas, con un papel de filtro y muy relevante en los procesos de admisión y en los supuestos de elaboración de informes y estudios. Este Gabinete técnico, creado en 1985 no es ni su sombra. Oculto y desconocido antaño, ha venido aumentando formal y materialmente sus competencias y la reforma de 2015 al regularlo de manera detallada por fin lo reconoce. De él se ha dicho ser la antesala del Supremo ${ }^{8}$.

El marco de la anterior reforma del 2013, expuesto en los debates de la tramitación parlamentaria de la ley y reflejado en los diarios de sesiones, era la necesidad de regeneración democrática, la búsqueda infatigable de un modelo de Consejo General del Poder Judicial independiente y garante de la independencia. ¿Cuál es el marco o el detonante de las reformas de 2015?

Hoy seguimos emplazados analizando la reciente reforma y preguntándonos por su utilidad o intención en la mejora de nuestro órgano de gobierno de jueces y magistrados. Y la prudencia nos obliga a tener también presentes todas esas reflexiones que de «modo sumergido» la soportan: las relaciones entre el Consejo y el Tribunal Supremo, la importancia de un buen diseño en los procesos de selección de nuestros jueces, la presencia renovada del elemento "político» en nuestro modelo de poder judicial, la implementación y construcción de la «responsabilidad de nuestros jueces»...

A lo largo de estas páginas vamos a reflexionar sobre todo ello en el ánimo de ofrecer nuevos enfoques a la principal demanda de nuestros días, una independencia judicial regenerada: «...Judges should be independent. Some might disagree about whether judges are as independent as is commonly supposed. Others might dispute whether judges are sufficiently independent. But few would disagree that judges should be equipped, personally and professionally to resolve disputes impartially, according to law and free from improper pressure whether from the parties to the dispute, governmental actors, pressure groups or other judges. This core understanding of judicial independence is based on the social logic of courts...»9

Para llevar a la práctica esos nuevos enfoques de independencia judicial sería posible elaborar una lista de aspectos a considerar, lista que en ningún caso po-

8 Franquet P., «La reforma de la LOPJ y la antesala del Tribunal Supremo», 31 julio de 2015, Legaltoday.com.

9 Graham Gee, Robert Hazell, Kate Malleson and Patrick O’Brien, The Politics of Judicial Independence in the UK's Changing Constitution, Cambridge University Press, London 2015, pp. 9-30. 
dría ser numerus clausus pero que sí comporta la esencia de un maduro concepto de independencia judicial en palabras de autores como Malleson, Gee o Hazell. Tales parámetros serían, entre otros, la limitación y tipificación de la promoción y la potestad disciplinaria, la ordenación detallada del mérito y la capacidad, la regulación pormenorizada de los salarios de los jueces y de sus posibles modificaciones o alteraciones. El diseño de modelos públicos claros y adecuados de financiación del sistema judicial, la plena autonomía de los jueces en sus decisiones judiciales, la inmunidad personal de ejercicio, una razonable y apropiada configuración de incompatibilidades con la actividad judicial, la garantía de asepsia necesaria respecto de las presiones políticas en el ejercicio de la función jurisdiccional, la aceptación del elemento político como parte necesaria en el diseño de un modelo judicial (evidentemente identificado, limitado y racionalizado), buenos y justos procesos de selección de jueces...

\section{LA REFORMA DE LA LEY ORGÁNICA DEL PODER JUDICIAL DE 2015: LA COMISIÓN PERMANENTE DEL CGPJ}

Desde la creación del Consejo en el año 1980 la preocupación por un Poder Judicial separado e independiente ha sido constante en nuestro constitucionalismo histórico. El título V del Proyecto de Constitución Federal de 1873 señalaba en una definición de aquél lo siguiente: «1. ${ }^{\circ}$ El Poder Judicial no emanará ni del Poder ejecutivo ni del Poder Legislativo». La fórmula elegida no resolvía qué comprendería exactamente pero desde luego lo que sí se quería poner de relieve era su tajante y rotunda separación de los otros poderes.

Nuestro constitucionalismo histórico arroja datos interesantes, no sabemos si suficientes y convincentes, para comprender las razones de nuestro constituyente optando por un modelo de gobierno judicial como el de nuestro artículo 122. El artículo 96 del Texto constitucional de la II República de 1931 decía: «...El Presidente del Tribunal Supremo será designado por el Jefe de Estado a propuesta de una Asamblea constituida en la forma que determine la Ley ${ }^{10}{ }$. Algunos autores han

10 Gazeta de Madrid 21 de junio de 1936, número 173, p. 2540: «...ARTÍCULO ÚNICO: Se modifican los artículo $1 .^{\circ}$ a $6 .^{\circ}$ de la Ley de 8 de octubre de 1932, sobre nombramiento del Presidente del Tribunal Supremo en los siguientes términos: artículo $1 .^{\circ}$ El Presidente del Tribunal Supremo será nombrado por el de la República, a propuesta de una Asamblea constituida por las siguientes personas: a) Veinticinco Diputados a Cortes designados por el Parlamento. b) Veinticinco miembros de las Carreras judicial y fiscal, [.... c) Veinticinco miembros distribuidos en la siguiente proporción: Primero. Los Decanos de los Colegios de Abogados de Madrid, Barcelona y Valencia. Segundo. Ocho representantes de la Administración general del Estado que designará el Consejo de Ministros entre los funcionarios que posean las cualidades de Letrado y categoría de Jefe Superior de Administración. Tercero. Siete Decanos del Colegio de Abogados elegidos por sorteo entre los de las doce Audiencias territoriales, deducidas las de Madrid, Barcelona y Valencia. Cuarto. Siete Catedráticos, por oposición, de la Facultad de Derecho, designados por el Consejo de Ministros. [.... ]»

Resulta también interesante recordar que el entonces presidente del Tribunal Supremo participaba activamente en la Comisión parlamentaria de justicia con voz y voto y disfrutaba además de la posibilidad de 
encontrado como primer precedente de nuestro Consejo esa Asamblea de la Segunda República capaz de diseñar una terna plural de candidatos pero paradójicamente sumisa a la decisión final del entonces presidente de la República Manuel Azaña.

Queremos poner de relieve dos rasgos que nuestro Constituyente del $78 \mathrm{im}-$ primió a la redacción del $122 \mathrm{CE}$. Dos características que pudiendo parecer coyunturales, la historia de Consejos vividos, ha confirmado: Por un lado la urgencia política y, por otro, la relativa tranquilidad de la delegación.

¿Por qué había cierta urgencia política en la creación del Consejo General del Poder judicial? Pues porque cuando se redactó la Ley orgánica de nuestro máximo intérprete, el Tribunal Constitucional LO 2/1979, de 3 de octubre, preveía que dos de sus doce magistrados serían nombrados por el Consejo General del Poder Judicial y así la Disposición Transitoria primera de la ley orgánica señalaba un plazo de tres meses desde la entrada en vigor de la ley para que el Consejo General del Poder Judicial elevará al Rey la propuesta de sus dos candidatos. Era obvio que urgía la creación del Consejo para que el sistema echara a andar.

Y, por otro lado, la redacción que se dio al 122 desvelaba abiertamente, desde la primera frase y por dos veces (art 122.1 y 2.) que sería la futura ley orgánica del poder judicial la que se encargaría de regular la constitución, funcionamiento, gobierno y estatuto de jueces y tribunales. Estaba claro que la vetusta Ley provisional del Poder Judicial de 15 de septiembre de 1870 llegaba a su fin. Y se ponía de relieve también el «descargo» o cierta tranquilidad para el constituyente que apostaba por un modelo de gobierno de jueces y magistrados independiente del ejecutivo y del Poder judicial, influenciado muy claramente por el Consiglio Superiore della Magistratura italiano a pesar de haber evolucionado de modo muy distinto a él, pero que en todo caso dejaba su articulación y concreción al legislador.

La Ley 1/1980, de 10 de enero, del Consejo General del Poder Judicial (artículo 34) ya reconocía la existencia de una Comisión permanente. Un órgano colegiado de reducido tamaño que para su válida configuración precisaba la asistencia de tres de sus cuatro miembros y que tomaría sus decisiones pudiendo éstas ser impugnadas ante el Pleno. Poco después, con la Ley orgánica 6/1985, de 1 de julio (artículo 130) se añadió, con relación a su composición, que de sus cuatro miembros, dos deberían pertenecer a la carrera judicial y los otros serían juristas de reconocida competencia. Por primera vez el Presidente del Consejo y por tanto del Tribunal Supremo del Poder Judicial podría pertenecer al cupo jurista o al judicial.

La Comisión permanente ha estado presente como órgano colegiado del Consejo desde sus orígenes, un órgano próximo al Presidente y reducido en su

proponer al Ministro de Justicia y a la Comisión parlamentaria, leyes de reforma judicial y medidas relativas a ascensos, traslados, promociones, etc. tanto de Jueces como de Magistrados. Ver Cavero Lataillade I., «ARTÍCULO 122. Comentarios a la Constitución española de 1978». Alzaga VillaAmil O., director, Tomo IX, Edersa 1998, p. 450 
composición que resultaría más ágil en la toma de todas aquellas decisiones que no precisaran la votación del Pleno. Este es desde luego el sentido de un órgano reducido dentro de otro, gestionar y decidir de manera más eficaz y eficiente. El primer paso, por tanto, será volver sobre la naturaleza y competencias del Consejo, en el ánimo de articular a posteriori la naturaleza y competencias de su comisión permanente. Nos resulta útil la enumeración de características que describe Cavero Lataillade sobre el CGPJ como un órgano constitucional, de ámbito estatal, de gobierno y de gestión que no forma parte del Poder Judicial, un órgano derivado (en gran parte de las Cortes Generales) colegiado, no representati$v 0^{11}$ y garantista, de responsabilidad indeterminada y por último, deliberante y de reflexión.

Resulta siempre más fácil tener claro lo que no se es, respecto de lo que se es, pero este paso del «ser» resulta imprescindible en el desarrollo adecuado de competencias, en el régimen de adopción de decisiones, en la valoración del logro de objetivos o en la intensidad permitida de control de su actividad ${ }^{12}$.

El nuevo Consejo de 2013 otorga un importante peso de sus decisiones a la Comisión Permanente. Y lo hace tan intensamente que se ha visto en este reducido órgano un foco de profundo descrédito para la supuesta tarea regeneradora del Consejo. Pérez Minaya llega a decir: «...que la politización ha sido el pecado capital de los sucesivos Consejos del Poder Judicial apenas puede discutirse. Elegidos por las Cortes Generales, los integrantes de nuestro órgano de gobierno han venido en no pocas ocasiones a reproducir, en pequeña escala, el equilibrio de fuerzas existentes en el mismo parlamento. [...] La LO 4/2013 alumbra un nuevo órgano de gobierno del Poder Judicial compuesto por cinco vocales: los integrantes de la Comisión Permanente... nos encontramos ante un fenómeno de concentración del poder en una parte, que, además se encuentra jurídicamente aislada e independiente del todo. ¿Alguien se imagina que el Secretario de Justicia pudiera adoptar decisiones sin facultad de control y revisión por el Sr. Ministro de

11 La Sentencia del Tribunal Constitucional 45/1986, de 17 de abril señala en su fundamento jurídico quinto: «...Además al configurarse constitucionalmente como su «órgano de gobierno», no podría ser, ni siquiera a efectos procesales, «representante» del Poder Judicial, pues ello estaría en contradicción con el principio constitucional de «independencia de Jueces y Magistrados» (arts. 117.1 C.E.) y ese presunto carácter representativo habría de admitirse también del lado pasivo, sujetando así al miembro integrante del Poder Judicial a instancias o actuaciones judiciales del propio Consejo...».

12 Es importante recordar, como antesala de la Ley Orgánica de 2013 y de 2015, la Resolución de 8 de marzo de 2012, BOE de 13 de marzo de 2012 Acuerdo de Consejo de Ministros por el que se crea una Comisión Institucional para la elaboración de una propuesta de texto articulado de Ley Orgánica del Poder Judicial y de Ley de Demarcación y Planta Judicial: «...La sociedad actual exige una mayor eficiencia y agilidad en el sistema de justicia, así como más garantías en la defensa de sus derechos e intereses. [...] Es esencial también profundizar en el objetivo de lograr una carrera judicial de excelencia, en la que el mérito, la capacidad y la especialización constituyan los principios básicos de la promoción profesional. [...] debe acometerse una profunda remodelación del órgano constitucional [...]procurando evitar la burocratización excesiva, redefiniendo sus competencias de acuerdo a la Constitución y diseñando una adecuada delimitación de éstas entre el Pleno y las distintas comisiones...» (la cursiva es nuestra). 
Justicia? El Pleno del Consejo no tiene facultad legal de revisar y dejar sin efecto acuerdos de la Permanente...» ${ }^{13}$

\section{Naturaleza de la Comisión permanente}

La Comisión permanente del CGPJ no tiene reflejo constitucional, la diseña el legislador de 1980 y se mantiene hasta nuestros días desde la primera ley orgánica del Poder Judicial de 1985 hasta la profunda reforma de 2013 y la posterior de 2015. A ella se han referido como «auténtico órgano nuclear del Consejo, en sustitución del Pleno que queda con una función más residual...» ${ }^{14}$

Señala Donaire Villa que a pesar de que la Constitución atribuye funciones al Consejo General en bloque, esto no deviene necesariamente incompatible con la previsión de la LOPJ en cuanto a la creación de mecanismos de «división del trabajo» ${ }^{15}$. Ahora bien, la pregunta que deberíamos hacernos es: ¿es la Comisión Permanente del CGPJ un órgano de división del trabajo? ¿ al servicio de quién? Varios aspectos deben analizarse para tratar de responder. El legislador de 2013 escribe en su exposición de motivos: «...La estructura así diseñada dista de ser un modelo presidencialista, pues la adopción de los acuerdos que no son competencia del Pleno corresponden esencialmente a la Comisión permanente no al Presidente...»

Los artículos 601 y 602 de la ley de 4/2013 establecen un modelo de comisión permanente elegida anualmente por el Pleno del Consejo, presidida por el Presidente de éste y compuesta por cinco vocales: tres procedentes del turno judicial y dos designados de entre juristas de «reconocida competencia».

A su vez, la ley explica la fórmula de la «rotación anual» de los distintos vocales que integran el Consejo, exceptuando a los de la Comisión disciplinaria, en aras de poder producirse la renovación anual de los vocales de la permanente y también en el ánimo de conseguir la presencia en la permanente de todos los vocales. Todos los vocales del Consejo en algún momento de su mandato deberán invertir un año de su actividad en la Comisión permanente.

Una pretensión que en principio se percibió como ilusionante y pluralista. Señalaba el vocal Enrique Lucas Murillo: «...todos nos sentimos orgullosos en aquel momento de contribución colectiva al acuerdo. Ni que decir tiene que el arreglo se logró porque se halló una fórmula asumida por todos que reflejaba en

13 Pérez Minaya, J.: «Crónica de una muerte anunciada. Breve autopsia del Consejo General del Poder Judicial», en Diario La Ley, n. ${ }^{\circ}$ 8126, Sección en Primera Persona, 15 Jul. 2013, Año XXXIV, Editorial La Ley.

14 Gerpe Landín M. y Cabellos Espiérrez A., «La reforma permanente: el Consejo General del Poder Judicial a la búsqueda de un modelo» en Revista Española de Derecho Constitucional, n. ${ }^{\circ}$ 103, enero-abril, CEPC, Madrid 2015, p. 15.

15 Donaire Villa F., «La renovada configuración de la Comisión Permanente del Consejo General del Poder Judicial tras la ley orgánica 4/2013» en Independencia Judicial y Estado Constitucional. El Gobierno Judicial, Aguiar De LuQue L., (editor), Tirant monografías 988, Valencia 2016, pp. 53 y ss. 
las comisiones, en especial en la Permanente, las distintas sensibilidades existentes en el Pleno y en la idea de que en las sucesivas renovaciones se seguiría el mismo método y se mantendría la concordia» ${ }^{16}$.

Pero además la expresión elegida por el legislador resultaba un tanto peculiar: «... se procurará la rotación anual del resto de los vocales en la composición anual de la Comisión permanente». No sólo la reiteración innecesaria del término anual llamaba la atención, también lo hacía la laxitud de los términos a la hora de referirse al hecho de la renovación/rotación. La naturaleza «prescriptiva» de un plazo temporal casaba mal con la fórmula permisiva «se procurará», sencillamente como fuente de inseguridad.

Otro elemento configurador de la Comisión permanente es el especial régimen de sus vocales. Sólo ellos estarán en dedicación exclusiva sin poder seguir desempeñando sus originarias funciones bien como juristas de reconocida competencia, bien como jueces o magistrados. Parece que asistimos a una categorización de los vocales dentro del órgano de gobierno de jueces y magistrados: distinto salario, distinta participación, distinta capacidad de decisión, distinta presencia y conocimiento de los asuntos del Consejo. Según el artículo 579.2 LOPJ sólo los vocales de la permanente pasarán a la situación de «servicios especiales» en su cuerpo de origen. Además tendrán incompatibilidad para desarrollar simultáneamente cualquier otra responsabilidad gubernativa en el ámbito judicial ${ }^{17}$, incompatibilidad que cesará al pasar al régimen de dedicación parcial fuera de la comisión permanente.

\section{Composición y características de la Comisión permanente: de cinco a siete vocales}

La comisión es un órgano colegiado ${ }^{18} \mathrm{y}$ reducido, esto es, una representación a pequeña escala de la totalidad del Pleno y su razón de ser es trabajar de manera

16 Texto del Voto particular que emite el vocal Enrique Lucas Murillo de la Cueva al acuerdo del Pleno sobre renovación de la Comisión permanente, de asuntos económicos y de igualdad, del Consejo General del Poder Judicial: «...El contraste entre los pasos dados en diciembre de 2013 y los seguidos en esta ocasión no puede ser más llamativo y desalentador. La elección que hicimos entonces estuvo presidida por la búsqueda del equilibrio entre las distintas sensibilidades del Consejo y la consecución de un acuerdo global. Esta primera renovación se ha caracterizado, sin embargo, por la cerrazón, la imposición y la discordia. Buena prueba de ello ha sido el resultado de la votación, unánime entonces, dividida ahora...».

17 FERnández Riveira R., op. cit., p. 165.

18 Carbonell Porras E., Los órganos colegiados. Organización, funcionamiento, procedimiento y régimen jurídico de sus actos; CEPC Madrid 1999; pp. 69 y ss. «...La opción organizativa por el carácter colegiado de un órgano administrativo está presidida por dos consideraciones que, por obvias, no pueden olvidarse; en primer lugar, la plurisubjetividad y, en segundo lugar, es necesario un determinado procedimiento para la formación de la voluntad colegiada que, por escasamente formal que sea, es más lento que cuando la decisión corresponde a un órgano unipersonal. El órgano colegiado ofrece la ventaja de permitir la participación de los particulares, la contraposición de intereses o el fortalecimiento del saber y la experiencia pues, con una com- 
más rápida y eficiente. Tan sólo se integraba por 5 vocales más el presidente en régimen de dedicación exclusiva. Ahora bien, tras la reforma de 2015 se modifica el artículo 601 LOPJ aumentándose el número hasta siete, cuatro procedentes del turno judicial y tres del turno de juristas.

¿Cuáles son las razones de tal incremento de vocales? Las explicaciones del legislador de 2015 no arrojan excesiva luz al asunto: «...Se trata de ajustes fruto de la experiencia de casi un año de funcionamiento del nuevo modelo de Consejo General de Poder Judicial. [...] el aumento del número de miembros de la Comisión permanente, que pasan de cinco a siete, significa que las importantes atribuciones que tiene encomendadas puedan ser ejercidas con plena dedicación por un número importante de vocales...»

Todo parece indicar que se opta por un pluralismo, supuestamente mayor, en las decisiones de la comisión permanente, que además se intuye una gran carga de trabajo que requiere más vocales con dedicación plena y que la experiencia de un año identifica como demasiado reducida una Comisión de tan sólo cinco vocales de entre 20 que constituyen el Pleno.

Ahora bien, no se refiere en la exposición de motivos el añadido del nuevo artículo 601 LOPJ con relación a la redacción de 2013: «...Con excepción de los miembros de la Comisión Disciplinaria, se procurará, previa propuesta del Presidente (la cursiva es nuestra), la rotación anual del resto de los Vocales en la composición anual de la Comisión Permanente...»

\section{Competencias de la Comisión permanente del Consejo}

La ley de 2013 asigna competencias a la permanente «por descarte» o de «modo indirecto». ¿Cuáles son las competencias de la Comisión permanente? Todas las que no estén atribuidas al Pleno o al resto de las comisiones del Consejo y todas las que ejercía la extinta comisión de calificación. La preparación de los nombramientos «discrecionales» pasa también a la Comisión permanente pero insiste el legislador que no se desapodera al Pleno que seguirá teniendo en las que denomina «decisiones auténticamente relevantes» como nombrar a los presidentes y a los magistrados del Supremo, aprobar los Reglamentos del Consejo o el Presupuesto.

En materia disciplinaria tampoco existe una asignación en positivo, pero sí puede «corregir» la inactividad del Promotor de la Acción disciplinaria ordenán-

posición racional, estos factores se aprecian mejor por varios sujetos, pero el inconveniente de la lentitud en la decisión. [...] Todo órgano colegiado se rige por unos principios comunes que persiguen que el órgano forme adecuadamente su voluntad, y que constituyen el procedimiento colegial. Sintéticamente son: la debida citación de los miembros, la efectiva celebración de la sesión y los mecanismos que aseguran la adecuada formación de la voluntad colegial (conocer e informarse sobre los asuntos a tratar, concurrencia de un número mínimo de miembros, votación...). 
dole, la incoación o prosecución de un procedimiento disciplinario. Lo aclara la exposición de motivos y el artículo 608 LOPJ explicando que, frente a la decisión del Promotor de la Acción disciplinaria de no iniciar expediente disciplinario o de archivar uno ya iniciado, se podrá interponer recurso ante la Comisión permanente y si esta decidiere estimar el recurso se iniciará o continuará el expediente de que se trate. Por lo tanto y dado que sus acuerdos no son recurribles en alzada ante el Pleno, podemos esbozar que no es verdad que la competencias «discrecionales» estén todas en manos del pleno, es evidente que hay un margen importante de discrecionalidad en la decisión de abrir o no un expediente disciplinario a un juez o magistrado.

No creemos apropiado dejar la potestad sancionatoria y/o disciplinaria en manos de un grupo de siete vocales. Y lo que es aún mejor, ¿qué órgano conoce en caso de que tales acuerdos de la comisión permanente (y del Pleno) sean recurridos? Pues según el 638 LOPJ (antiguo 143 LOPJ), será la sala de lo contencioso-administrativo concretamente la sección especial integrada por el presidente de la sala de lo contencioso-administrativo del Tribunal Supremo que la presidirá y por los demás presidentes de sección de dicha sala. Y, ¿quién nombra a los magistrados que integran esa sala tercera y sus diferentes secciones? Pues en la medida que todos ellos son nombramientos «discrecionales» el artículo 599.1.4. ${ }^{\circ}$ LOPJ concede en régimen exclusivo tal competencia al Pleno del Consejo.

Y si resulta sensato y, hasta conveniente, que la palabra definida no debe entrar en la definición, parece obvio o, cuando menos imprescindible, que el órgano que decide sobre lo que se «impugna» no puede estar nombrado por quién acuerda lo impugnado. Problema que en su momento ya se planteó el Tribunal Constitucional en la sentencia108/1986, de 29 de julio, F.J. 10. ${ }^{\circ}$ : «la posición de los integrantes de un órgano no tiene por qué depender de manera ineludible de quienes sean los encargados de su designación sino que deriva de la situación que les otorgue el ordenamiento jurídico. En el caso del Consejo, todos sus vocales, incluidos los que forzosamente han de ser propuestos por las Cámaras y los que lo sean por cualquier otro mecanismo, no están vinculados al órgano proponente, como lo demuestra la prohibición del mandato imperativo (art. 119.2 de la L.O.P,J.) y la fijación de un plazo determinado de mandato (cinco años); que no coincide con el de las Cámaras y durante los cuales no pueden ser removidos más que en los casos taxativamente determinados en la Ley Orgánica...» Desgraciadamente los hechos han confirmado, una vez más, que la práctica desvirtúa la teoría y desde luego el «deber ser».

Dicho en otros términos, supongamos que se decide por la comisión permanente nombrada por el Pleno del Consejo, en contra de la opinión del Promotor de la Acción disciplinaria, abrir expediente sancionador a un magistrado, siendo tal acuerdo ejecutivo, no recurrible en alzada al Pleno y, finalmente impugnado por el magistrado afectado. Tal impugnación deberá incoarse ante la sala tercera del Supremo, en la sección especial referida nombrada toda ella por el Pleno del Consejo. ¿No estaremos forzando la senda de la «discrecionalidad»? ¿No estaremos 
violentando la asignación indirecta o «por descarte» de competencias a este órgano colegiado de vocales en exclusividad? ¿No estaremos agostando el espacio necesario entre el órgano de gobierno de jueces y magistrados y el poder judicial, como conjunto de jueces y magistrados gobernados por aquél?

\section{El régimen jurídico de los acuerdos adoptados por la Comisión permanente}

Tal y como se ha expuesto en el apartado anterior, los acuerdos de la Comisión permanente se adoptan por mayoría de los miembros presentes, artículo 630.1: «Los acuerdos de los órganos colegiados del Consejo General del Poder Judicial serán adoptados por mayoría simple de los miembros presentes, salvo cuando esta Ley Orgánica disponga otra cosa. Quien presida tendrá voto de calidad en caso de empate» ${ }^{19}$.

Las deliberaciones de las decisiones tendrán carácter «reservado», debiendo sus componentes «guardar secreto» de las mismas. Ahora bien, todos los acuerdos serán siempre «motivados» $\mathrm{y}$ «documentados» por el Secretario general, debiendo ir firmados por quien los haya presidido. Serán inmediatamente «ejecutivos» salvo que, en caso de impugnación, el órgano que conoce de la misma de oficio o a instancia de parte decida su suspensión si esta pudiera originar perjuicios de imposible o difícil reparación o cuando esté previsto así en la ley. Los actos de la Comisión permanente «ponen fin a la vía administrativa» por lo que sólo serán recurribles, como ya hemos anunciado, ante la sala de lo contencioso-administrativo del Tribunal Supremo. Es importante recordar la antigua regulación del régimen de impugnaciones de las resoluciones definitivas tanto de la Comisión permanente como de la disciplinaria, porque los acuerdos de ambas eran impugnables en alzada ante el Pleno del Consejo.

Del estudio de los artículos 629 a 642 de la LOPJ que se agrupan bajo el Título V: Del régimen de los actos del Consejo General del Poder Judicial y de su contraste con regulaciones previas en versiones anteriores de esta ley orgánica podemos reflejar algunas cuestiones:

a) La relación de control que el Pleno ejercía sobre la comisión permanente se ha perdido. Y ello convierte en «injustificable» la razón de ser de la Comisión permanente precisamente porque la teoría que avala su creación es la de un órgano «al servicio del Pleno».

b) Además, se establece cierta tipología y/o categorización, implícita, respecto de todos los acuerdos o actos adoptados por el Consejo. La forma nominal adoptada por ellos lo refleja. En el articulado se alude a: «actos

19 FERnández Riveira R., op. cit., p. 169. 
del Pleno y de la comisión permanente», otras veces se dice «actos de trámite» o «restantes acuerdos», pero lo que no cabe duda es que hay un tipo de acuerdos de entre todos que adquieren un protagonismo especial y son: «los nombramientos de Presidentes y Magistrados». Para ellos se estipula, la forma de Real Decreto, la firma del Rey, el refrendo del Ministro de Justicia y la publicación en el Boletín Oficial del Estado. También el legislador distingue los «actos de nombramiento de jueces» que adquieren la forma de Orden y se publicaran en el BOE, la aprobación de Reglamentos que se publicarán en el BOE y, por último, los que llama «restantes actos» que sólo se comunicarán a las personas u órganos que deban cumplirlos o conocerlos. Tales distinciones denotan cierta jerarquización en los actos descritos que está presente desde la primera redacción de la LOPJ y que es una buena herramienta para llevar a cabo, en cuanto a competencias se refiere, un estudio de «trazabilidad» del papel de la Comisión permanente desde su creación.

\section{El proceso de renovación de la Comisión permanente: el episodio vivido de la no renovación}

Recordemos otra vez el artículo 601.2 LOPJ: «...Con excepción de los miembros de la Comisión Disciplinaria, se procurará, previa propuesta del Presidente, la rotación anual del resto de los Vocales en la composición anual de la Comisión Permanente».

¿Qué efectos produce entonces la no renovación de la Comisión, si previamente se ha "procurado» pero no se ha logrado con éxito? Tal como ha sido redactado en la ley por el legislador: ninguno. Gerpe Landín y Cabellos Espiérrez dicen: «Quiere con ello decirse que, con la ley en la mano, no se sabe si va a haber rotación anual o no. ¿Pudiera, por tanto, pasarse una comisión permanente cinco años con los mismos miembros? ¿Esto supondría haber vulnerado la ley o, como parece más probable, no habría vulneración al hablar ésta simplemente de «procurar»? ¿Bastaría sí, no obstante, se quisieran guardar mínimamente las formas, con cambiar un vocal de vez en cuando, ni siquiera cada año, para que se apreciara que en algo se ha procurado rotar? ${ }^{20}$ »

Premonitorios han resultado los comentarios doctrinales expuestos pues transcurrido un año desde la primera comisión permanente del nuevo Consejo, el Pleno del mismo decidió su no renovación (acuerdo 4.1 del orden del día del Pleno de 29 de enero de 2015) lo que fue impugnado y objeto de dos votos particulares interpuestos por varios vocales discrepantes del Consejo. Se incumplió el artículo 601 de la ley y así catorce votos a favor y siete en contra decidieron la no renovación de la comisión permanente del Consejo a excepción de la vocal Merce Pigem

20 Gerpe Landín M., y Cabellos Espiérrez M.A., op. cit., pp. 13-44. 
que presentó, por otras razones, su dimisión en el cargo motivando su sustitución por Núria Díaz Abad como única voz nueva en la Comisión cuando se cumplía un año.

El 29 de enero de 2015, el Pleno del Consejo General del Poder Judicial en su punto IV acuerda, entre otros asuntos, nombrar como vocales de su Comisión Permanente, (según los términos del artículo 601 de la Ley orgánica del Poder Judicial), a los mismos vocales que ya nombró el 20 de diciembre de 2013.

La celebración del Pleno del CGPJ estaba prevista para el día 18 de diciembre de 2014 y seis días antes, varios vocales solicitan, la inclusión en el orden del día de la elección anual de la Comisión Permanente mediante el procedimiento de voto por sistema mayoritario corregido. Asimismo tres vocales del CGPJ con anterioridad a la celebración del Pleno presentaron su candidatura para formar parte de la misma. El artículo 18.5 del Reglamento de Organización y Funcionamiento del CGPJ de 22 de abril de 1986, establece que los vocales del Consejo tienen derecho a formular propuestas escritas y a su inclusión en el orden del día de las reuniones del Consejo. Es el propio presidente del Consejo, quién decide retirar el punto I. 4 del orden del día del pleno de 18 de diciembre (titulado «Propuesta de composición de las comisiones del CGPJ para el año 2015) en el ánimo de lograr el mayor grado de acuerdo posible.

En un segundo intento y estando prevista la celebración del pleno el día 29 de enero de 2015, los mismos vocales referidos, seis días antes vuelven a gestionar la inclusión en el orden del día de las mismas propuestas retiradas. Otra vez el presidente deniega la posibilidad de someter a votación ambas solicitudes. Y se abordó finalmente en el Pleno la propuesta IV del orden del día titulada exactamente igual que en diciembre: «Propuesta de la composición de las comisiones del CGPJ para el año 2015», «que entonces no exponía nombres concretos», lo que se sometió a votación, por decisión del Presidente, fue una determinada composición con nombres y apellidos de cada comisión. El artículo 45 del Reglamento de organización y funcionamiento ya mencionado establece que no podrán adoptarse acuerdos sobre temas o materias no incluidos en el orden del día, o carentes de propuesta escrita, salvo que, hallándose presentes todos los miembros del Consejo, se decida lo contrario por unanimidad. Las cosas se hicieron incumpliendo el régimen de acuerdos connatural a los órganos colegiados (respeto al pluralismo y diversas sensibilidades, anuncio con antelación suficiente de los puntos del orden del día, claridad en el régimen de adopción de acuerdos o mayorías).

Los votos particulares que se suscriben por varios vocales del Consejo señalan que el acuerdo global del pleno de 29 de enero de 2015 se obtuvo con: «cerrazón, imposición y discordia.... ${ }^{21}$.

21 Lucas Murillo E., expone en su voto particular de 2 de febrero de 2015: «...el presidente ha roto el equilibrio. En efecto, tras la posposición in extremis de este asunto, que debía haberse resuelto en diciembre 
Como órgano colegiado la comisión permanente debe respetar el pluralismo estructural del órgano de gobierno de jueces y magistrados. El pluralismo es garantía irrenunciable de cualquier órgano colegiado. Pluralismo necesario como se ha visto en otros supuestos previos: para elegir al Presidente del Tribunal Superior de Justicia de Murcia ${ }^{22}$, para decidir convocar a concurso la provisión de la plaza del Juzgado número cinco de la Audiencia $\mathrm{Nacional}^{23}$, para decidir brindar o denegar amparo a los magistrados de la Sala Penal de la Audiencia Nacional cuando lo solicitaron al sentirse presionados por las duras declaraciones vertidas contra ellos desde el gobierno ${ }^{24}$, pluralismo necesario para decidir la pérdida de la condición de magistrado del Tribunal Supremo en caso de presentarse como candidato en unas elecciones a cargos públicos representativos ${ }^{25}$.

de 2014, ha hecho oídos sordos a las llamadas a la negociación y al acuerdo y faltando gravemente a su compromiso. Que consta en acta, de negociar la renovación de la Comisión Permanente, ha forzado la ratificación de su propuesta personal como si estuviera discutiendo la remodelación de su gabinete...».

22 Nota de Prensa del CGPJ, jueves 26 de mayo de 2016, El Consejo General del Poder Judicial nombra a Pascual de Riquelme presidente del Tribunal Superior de Justicia, juez a quien el Tribunal Supremo anuló en su nombramiento por entender éste defectuosa e insuficientemente motivado, Sentencia 1033/2016, de 10 de mayo del pleno de la sala $3 .^{\text {a }}$ del TS. En el Pleno de la referida sala, 18 magistrados votaron a favor de anular la designación de Riquelme, frente a 15 que votaron en contra.

23 Diario ABC, 10 diciembre de 2014, El 9 de diciembre de 2014, la Comisión permanente del Consejo decidió sacar a concurso la plaza que ocupa en comisión de servicios el Juez Pablo Ruz desde junio de 2013, este Juez es uno de los magistrados que instruye el mayor número de causas de corrupción en nuestro país: Gürtel, papeles de Bárcenas, Pujol, Prenafeta, Caso SGAE... La comisión permanente compuesta entonces por cinco vocales sólo emitió un voto en contra y cuatro a favor de tal decisión.

24 Diario ABC, 4 diciembre de 2014, El motivo de tal intromisión sería la decisión de la Sección Primera de la Sala de lo Penal de la Audiencia Nacional de excarcelar a presos etarras aplicando la decisión marco de la UE de 2008, que permite acumular penas dictadas a presos españoles en otros países. La ley de trasposición de esta normativa, y que restringe sus efectos a las sentencias dictadas con posterioridad a agosto de 2010 entró en vigor un día después de las puestas en libertad, el pasado día 3. El entonces Ministro del Interior Jorge Fernández Díaz calificaba la decisión de lamentable desde todos los puntos de vista también desde el punto de vista jurídico. Estos hechos llevaron a que la Comisión permanente emitiera el 17 de diciembre de 2014 un comunicado al respecto: «... a la vista de diferentes declaraciones de responsables públicos, la Comisión Permanente recuerda, como ya lo hizo el 23 de enero de 2014 y el 30 de junio de 2014, que en un Estado Democrático de Derecho, los/las jueces/juezas y magistrados/as, como titulares del Poder Judicial, asumen la decisiva e indispensable labor de proteger y garantizar los derechos y libertades en condiciones de independencia, imparcialidad y responsabilidad, constituyendo precisamente el ejercicio independiente, imparcial y responsable de la jurisdicción su fuente de legitimidad democrática».

25 Diario El País de 19 mayo de 2016, La Comisión Permanente del Consejo ha decidido en sesión de 19 de mayo de 2016 por cuatro votos a favor y tres en contra: «... Declarar a la magistrada del Tribunal Supremo Margarita Robles Fernández en la situación administrativa de excedencia voluntaria en la Carrera Judicial, prevista en el artículo 356.f) de la Ley Orgánica del Poder Judicial, desde el día 13 de mayo de 2016, con los efectos previstos en dicho artículo y en el artículo 184.1 del Reglamento 2/2011, de 28 de abril, de la Carrera Judicial, disponiendo de un plazo de 30 días naturales siguientes a la fecha de proclamación definitiva de candidatos electos para solicitar el reingreso en el servicio activo o en la situación administrativa que corresponda, y si no lo hiciera será declarada, en su caso, en situación de excedencia voluntaria por interés particular». Pero además el mismo día y en la misma sesión de la comisión permanente se adopta como decisión la pérdida de la condición de magistrada del Tribunal Supremo de Margarita Robles, como consecuencia de la concesión de la excedencia voluntaria prevista en la letra f) del artículo 356 de la LOPJ, quedando así ésta integrada en la categoría de magistrada». Señala a este respecto el VOTO PARTICULAR suscrito el 20 de mayo de 2016 por Álvaro Cuesta Martínez y Pilar Sepúlveda García de la Torre: «... un pronunciamiento 
Pero si el pluralismo fue una de las razones en el diseño de la comisión permanente de la reforma de 2013 y un argumento, una vez más, para justificar la ampliación de cinco a siete vocales, en la reforma de 2015, la renovación anual de la comisión es requisito sine qua non para poder salvaguardar ese pluralismo. Será el Pleno quien tenga que decidir cómo se lleva a cabo la «rotación» de este órgano colegiado y no debería aceptarse, en ningún caso, una no renovación que enturbia y dificulta un ejercicio plural e independiente de las tareas de los vocales.

Claro que es determinante para los vocales estar en la comisión permanente al menos durante un año, claro que es importante respetar los turnos de rotación que garantizan la voz y el voto de todas las sensibilidades en el Consejo. El Pleno debe elegir a los que formaran parte de las comisiones, pero elegir no es aprobar o ratificar. En iguales términos lo explicaba Enrique Lucas Murillo en el ya citado voto particular al acuerdo del Pleno sobre la renovación de las comisiones del Consejo: «....no cabe aquí la mera aprobación de propuestas cerradas ni de ratificar lo previamente decidido por el presidente ${ }^{26}$.

\section{EL NUEVO GABINETE TÉCNICO AL SERVICIO DEL TRIBUNAL SUPREMO}

El Gabinete Técnico del TS ha sido renovado también en 2015. Su paso del Reglamento de Organización y Funcionamiento (arts. 99 a $104^{27}$ ) a su articulación pormenorizada en la LOPJ (arts. 61 bis a 61 sexíes) le ha colocado en una importante posición de poder al servicio del Presidente del Consejo. Y todo ello en un momento vital en el que la reforma de 2015 de la Ley orgánica del Poder Judicial (LO 7/2015, de 21 de julio) en su disposición final tercera reforma la Ley reguladora de la Jurisdicción contencioso administrativa, Ley 29/1998, de 13 de julio, introduciendo el denominado «interés casacional objetivo» como elemento que rediseña el viejo recurso de casación. Una reforma sin precedentes que está

extemporáneo o innecesario. [...] En este momento, lo único que debería proceder como pronunciamiento por parte de la Comisión permanente, es la resolución sobre la situación de excedencia que solicitaba para concurrir a las elecciones generales. Por tanto, el acuerdo se extralimita absolutamente en relación a la petición realizada, y efectúa un pronunciamiento que únicamente resultaría procedente en un momento ulterior, a saber, cuando la magistrada ya en situación administrativa de servicios especiales (en caso de resultar elegida diputada) solicitara el reingreso al servicio activo...».

26 «...La carencia de una norma que regule esta relevante cuestión (todavía no se ha elaborado un Reglamento de Organización y Funcionamiento del CGPJ, tal y como se exponía en la Ley orgánica 4/2013), condena al Consejo a moverse en la inseguridad jurídica que supone estar al albur de lo que en cada Pleno se diga y haga y, en definitiva, a lo que el presidente quiera interpretar en cada caso al dirigir y ordenar los debates...». LuCAs Murillo E., VOTO PARTICULAR de 20 de mayo de 2016.

27 Acuerdo de 22 de abril de 1986, del Consejo General del Poder Judicial, por el que se aprueba el Reglamento de Organización y Funcionamiento del Consejo General del Poder Judicial. Última modificación de 5 de marzo de 2010. 
hoy siendo estudiada y encajada en nuestro sistema jurídico porque aún son impredecibles sus primeros efectos.

Dice nuestro legislador que: «...con la finalidad de intensificar las garantías en la protección de los derechos de los ciudadanos la ley opta por reforzar el recurso de casación como instrumento por excelencia para asegurar la uniformidad en la aplicación judicial del derecho. De esta forma el recurso de casación podrá ser admitido a trámite cuando invocada una concreta infracción del ordenamiento jurídico, tanto procesal como sustantiva o de la jurisprudencia, la Sala de lo Contencioso-administrativo del Tribunal Supremo estime que el recurso presenta interés casacional objetivo para la formación de jurisprudencia. Con la finalidad de que la casación no se convierta en una tercera instancia, sino que cumpla estrictamente su función nomofiláctica, se diseña un mecanismo de admisión de los recursos basado en la descripción de los supuestos en los que un asunto podrá acceder al Tribunal Supremo por concurrir un interés casacional. La sala de casación tendrá que apreciar que existe «interés casacional objetivo» motivándolo expresamente en el auto de admisión. El recurso deberá ser admitido en determinados supuestos, en los que existe la presunción de que existe interés casacional objetivo»

La compleja reforma, deberá entrar en vigor el 22 de julio de 2016 y puesta ante el espejo, (pendiente de un estudio en profundidad que, evidentemente no puede ser objeto de estas páginas), refleja: ser una reforma diseñada a imagen y semejanza de la «especial trascendencia constitucional» (LO 6/2007, 24 de mayo) para el recurso de amparo ${ }^{28}$; refleja que se articula a modo de certiorari para homogeneizar y «sanear» la casación; que reestructura el fondo y la forma ${ }^{29}$ de la aún

28 CANCiO FERnÁndez R.C., «La Sala tercera del Tribunal Supremo ante el nuevo modelo de casación», Revista Aranzadi Doctrinal 4, abril 2016; «...según Díez Picazo Giménez el Tribunal Supremo no está para crear jurisprudencia, rol que conlleva el riesgo de un deslizamiento (con tintes ideológicos muy contrapuestos a la esencia de la independencia judicial) a que los casos y las sentencias sean solo el vehículo de ejercicio por el Tribunal Supremo de una suerte de poder normativo paralelo, lo que en Estados Unidos se conoce como docket setting process o control de la agenda de señalamientos del Tribunal Supremo, mecanismo al que muchos consideran más una forma de hacer política que una ordenación gubernativa del funcionamiento del Tribunal...».

29 Santamaria Pastor J.A., «Una primera aproximación al nuevo sistema casacional», Revista de Administración Publica, número 198, septiembre-diciembre 2015, p. 30; Santamaría critica, entre otros, los aspectos formales de la reforma que tilda de «ocurrencia» y que diseñan un peculiar órgano de admisión o inadmisión del recurso, según el nuevo artículo 90.2 LJCA; Señala el referido precepto que: «2. La admisión o inadmisión a trámite del recurso será decidida por una Sección de la Sala de lo Contencioso-administrativo del Tribunal Supremo integrada por el Presidente de la Sala y por al menos un Magistrado de cada una de sus restantes Secciones. Con excepción del Presidente de la Sala, dicha composición se renovará por mitad transcurrido un año desde la fecha de su primera constitución y en lo sucesivo cada seis meses, mediante acuerdo de la Sala de Gobierno del Tribunal Supremo que determinará sus integrantes para cada uno de los citados periodos y que se publicará en la página web del Poder Judicial». Sobre este artículo señala Santamaría: «... Es realmente muy difícil cometer mayor número de desaciertos en un solo precepto legal, modificando las raras cosas que funcionan bien para sustituirlas por otras que es absolutamente seguro que funcionarán mal. Quien ha de velar por la identidad de criterios aplicados por un órgano colegiado es precisamente su presidente, no cualquiera de sus miembros por inteligentes y capaces que sean; máxime, cuando los criterios a unificar se refieren a cuestiones tan impalpables y opinables como es la existencia de interés casacional...». 
vigente casación; y que, sin duda ha otorgado un papel relevante al Gabinete Técnico del Tribunal Supremo.

Esta última preocupación simple punta de iceberg, se despliega a nuestro juicio ocultando una preocupante parte sumergida ¿Qué papel real se otorga en la sombra a este cuerpo de Letrados del Gabinete y a su Director General? ¿Será un órgano técnico o, por el contrario, la exigencia y profundidad del estudio y respuesta en los procesos de admisión o inadmisión en la nueva casación lo convertirán en un órgano político? ${ }^{30}$ ¿Qué proceso se ha diseñado por la ley para nombrar a los miembros del Gabinete?

Las respuestas a tales cuestiones habrá que comenzar a buscarlas en: a) la regulación del Gabinete Técnico por la ley pero, desde luego, b) en las competencias reales que éste asumirá en el inminente futuro de indudable aumento de casaciones y de formación necesaria de los criterios «homogéneos» sobre la concurrencia del interés casacional.

Dos tareas que, como agua de mayo se esperan y que en su día hizo la sentencia 155/2009 de 25 de junio del Tribunal Constitucional en aras de granjear seguridad jurídica tras el nuevo amparo objetivo de la «especial trascendencia constitucional» en su reforma de 2007.

El Gabinete Técnico del Tribunal Supremo se crea en 1985 y así el artículo 163 de la Ley orgánica del poder judicial señalaba que: «En el Tribunal Supremo, y bajo la dependencia directa de su Presidente, funcionará un Gabinete Técnico de documentación e Información. La ley determinará su composición y plantilla». Este órgano de apoyo y asesoramiento se regulaba en los artículos 99 a 104 del Reglamento de organización y funcionamiento del Consejo General del Poder Judicial (aprobado por Acuerdo de 22 de abril de 1986 del CGPJ) pues en la Ley no se hacía ninguna otra referencia a su composición, funciones o relevancia. Sus funciones, claramente entonces delimitadas en tres áreas, se articulaban en cuatro órganos internos bien diferenciados: el Director del Gabinete Técnico, la sección de Estudios e Informes, la sección de Relaciones Institucionales e Internacionales y la de Estudios sobre organización y racionalización de la Oficina Judicial.

Pero tal como se desprende de la nueva regulación de 2015, la Presidencia del Consejo, al mismo tiempo del Tribunal Supremo, es también y por tercera vez, la superior dirección del Gabinete Técnico, «tres cargos y competencias distintas y una sola persona verdadera». El artículo 61 ter así lo señala: «La superior dirección del Gabinete Técnico será ejercida por el Presidente del Tribunal Supremo,

30 Santamaría Pastor J.A., op. cit., p. 39; «... un incremento considerable del tiempo de estudio que requerirá cada uno de los recursos: en la actualidad, y si mis informaciones no son inexactas, cada recurso es objeto de un estudio superficial, referido a cuestiones puramente formales, en el trámite de admisión regulado en el artículo 93 (que es realizado en una primera fase por los Letrados del Gabinete) y, posteriormente, de un examen en profundidad por parte del Magistrado de la Sección al que corresponda preparar la ponencia. La implantación del sistema de certiorari obligará a transformar el primer análisis de admisión en un examen a fondo del recurso, $[\ldots]$ en el que habrá que formar criterio sobre la concurrencia o no de interés casacional...». 
en caso de delegación de éste, por el Vicepresidente del Tribunal Supremo». La lectura de estos preceptos pone de relieve la subordinación de este órgano en su composición, en sus funciones y en su control a la Presidencia del Consejo.

\section{Subordinación en su composición}

El Gabinete se compone de un Director y de Letrados que podrán ser miembros de la carrera judicial o juristas, heterogeneidad que también se abraza por primera vez tras la reforma de 2015. Pero quién nombra tanto a uno, como a otros, será decisivo desde luego.

El artículo 61 quáter,1. expone: «...El Pleno del Consejo General del Poder Judicial nombrará al Director del Gabinete técnico, a propuesta vinculante del Presidente del Tribunal Supremo, debiendo acreditar los requisitos legalmente exigidos para poder acceder a la categoría de Magistrado del Tribunal Supremo, teniendo dicha consideración, a efectos representativos, mientras desempeñe el cargo». Por lo tanto, es el Presidente del más alto Tribunal quien decide. Porque, si para que esté válidamente constituido el Pleno es suficiente la presencia de al menos diez vocales (doce para nombrar al presidente del Consejo) y el propio presidente (arts. 603 y 604.4 LOPJ), si sabemos que las decisiones en el Pleno se toman por mayoría de los miembros presentes (630.1 LOPJ), si sabemos también que el voto del presidente dirimirá el empate en caso de producirse éste, resulta a todas luces innecesario, por redundante, que el legislador además haya introducido que sólo será Director aquél que el Presidente del Consejo y de modo vinculante proponga. Un exceso de celo de nuestro legislador que choca paradójicamente con la intención de la exposición de motivos, una decidida intención de evitar un modelo «presidencialista». No basta el deseo o la intención de no querer concentrar competencias y decisiones en una determinada figura unipersonal, se requiere articular procedimientos y actuaciones al servicio del conveniente pluralismo y representación de las diversas sensibilidades ${ }^{31}$.

31 Diario de Sesiones, número 567, Congreso de los Diputados, Comisión de Justicia, 13 mayo de 2014, «...Aunque el artículo 564 de la Ley Orgánica del Poder Judicial establece que fuera de la remisión anual a las Cortes Generales de la memoria sobre el estado, funcionamiento y actividades del propio Consejo General del Poder Judicial y de los juzgados y tribunales no recaen ni sobre el presidente del Tribunal Supremo ni sobre los vocales del consejo deber alguno de comparecer por razón de sus funciones, es lo cierto que nada impide que la colaboración y diálogo entre el CGPJ y el Parlamento sean permanentes. Por eso quiero transmitirles que mi voluntad y la de los vocales del Consejo es la de impulsar la máxima colaboración institucional con las Cortes Generales, ...» ¿Cuál es entonces la razón de ser del artículo 564 de la ley orgánica del poder judicial? ver Fernández Riveira R., op. cit., nota 2, p. 2; En el mismo Diario de Sesiones se dice también: «...Nuestro quinto compromiso es alcanzar acuerdos por amplias mayorías. [...] evitando a nivel interno facciones partidistas en el sentido que ya denunció la sentencia del Tribunal Constitucional 108/1986. No dudo que ese es el empeño sincero y primordial de los vocales del Consejo. Aunque la actual regulación contenida en la Ley orgánica 4/2013 de reforma del consejo no exige mayoría cualificada en materia de nombramientos, es nuestro deseo que todos se hagan con la más amplia mayoría, lo que tiende a asegurar el acier- 
Y, ¿qué ocurre por otro lado, con el resto de miembros asesores y asistentes del presidente o denominados Letrados? Los letrados podrán ser miembros de la carrera judicial o juristas, no obstantes tendrán cierta preferencia los de procedencia judicial con al menos diez años de antigüedad. Todos ellos serán designados por el Presidente del Tribunal Supremo (art. 61, bis.4 LOPJ). Una vez nombrados como Letrados, el cargo en principio durará un año, pero podrán ser prorrogados a propuesta del Presidente «por sucesivos periodos de tres años» sin que quede establecido un límite temporal máximo. Y por último, se señala también que en caso de incumplimiento grave en el desarrollo de sus competencias podrán ser cesados en el cargo, (art. 61, quinques, 1 LOPJ). Pero será el Presidente, una vez más, quién ostente tal facultad de cese.

La reforma de 2015 entiende que está pendiente la regulación de las normas de funcionamiento del Gabinete Técnico y así la sala de gobierno del TS a propuesta del Presidente deberá aprobar las mismas (art. 61 sexíes LOPJ).

\section{Subordinación en sus funciones}

Las funciones de este órgano técnico son dos muy relevantes: a) Asistencia al Presidente y a las diversas salas del Tribunal Supremo en los procesos de admisión de los asuntos de que éstas conozcan y b) Elaboración de los «estudios e informes» que les soliciten.

Y nuestra reflexión avanza cuestionándose, que si la «admisión» de los recursos de casación ha cambiado, tras convertirse ésta en esa suerte de certiorari que espera de los magistrados de la sala una respuesta profunda y un juicio objetivo de la conveniencia o no de que la sala deba crear jurisprudencia sobre un determinado asunto, será vital cómo el Tribunal selecciona los asuntos que sí y los asuntos que no, según sus «criterios de admisión», terminarán en un fallo casacional (certhworthy cases, según el modelo procesal americano). No olvidemos además, que frente a la inadmisión de la antigua casación por providencia, se exige ahora tras la reforma, auto de admisión o inadmisión motivado (art. 88.2 LJCA). Todo ello representa sin duda un cambio de mentalidad profundo. Si la Sala tercera asume, por fin (con el nuevo interés casacional objetivo), ese rol siempre pospuesto cuasilegislativo vía función interpretativa (y de nuevo la melancolía de constitucionalista nos traslada ante esa dimensión objetiva del recurso de amparo

to de los mismos. Unos buenos nombramientos procuran un mejor servicio al ciudadano y para nosotros el ciudadano es siempre el destinatario final de nuestras decisiones...» ¿Por qué entonces modificar la regla de adopción de los acuerdos del Consejo que exigía antes mayoría cualificada en su antiguo artículo 127 ? No obstante otras opiniones se han manifestado a este respecto, fruto sin duda de una diferente lectura que no compartimos, ver HeRnÁndez RAmos M., «El cambio de paradigma en el control del poder judicial como institución en España. De la responsabilidad judicial la judicial accountability» en Independencia Judicial y Estado Constitucional. El Estatuto de los Jueces, Monografías Tirant lo Blanch 1026, Valencia 2016, pp. 173-174. 
a la que la exposición de motivos de la reforma de la LOTC de 2007 se refería ${ }^{32}$ ), será necesario apuntalar y repensar desde luego la formación y cualificación del personal del Gabinete Técnico y, lo que es aún más importante, su legitimidad para «tamañas» competencias ${ }^{33}$.

Los criterios de selección de los Letrados del Gabinete, el estatuto jurídico de sus miembros y sus «normas de funcionamiento» adquieren por tanto vital importancia.

a) ¿Cómo se selecciona a los Letrados? ¿Cuántos Letrados integran el Gabinete Técnico? «...El Ministerio de Justicia, oída la Sala de Gobierno del Tribunal Supremo y previo informe del Consejo General del poder judicial e informe favorable del Ministerio de Hacienda y Administraciones Públicas, determinará la composición y plantilla del Gabinete Técnico» (art. 61 bis.5 LOPJ). Pero «por razones coyunturales y debidamente justificadas...» el CGPJ y la Sala de Gobierno del TS, sumados al Ministerio de Justicia podrán adscribir temporalmente, con el límite temporal de un año, letrados al servicio del Gabinete. ¿Cuántos? La ley responde que un número adicional ${ }^{34}$. A su vez, el art. 61 quáter establece que los letrados se seleccionarán por «concurso de méritos» estableciéndose en el anuncio de la convocatoria los criterios de selección. Pero tanto la elaboración de la propuesta de letrados como su elevación al Pleno del CGPJ, será competencia del Presidente del TS.

b) Respecto al estatuto básico de los letrados, la ley señala en la Disposición Final octava que en el plazo de un año el Gobierno remitirá a las Cortes

32 Exposición de motivos LEY ORGÁNICA 6/2007, de 24 de mayo, por la que se modifica la Ley Orgánica 2/1979, de 3 de octubre, del Tribunal Constitucional: «...Por esta razón, las reformas que se abordan van dirigidas a dotar al amparo de una nueva configuración que resulte más eficaz y eficiente [...] se puede destacar el cambio en la configuración del trámite de admisión del recurso,...».

33 CANCIO Fernández R.C., op. cit., «...señala cínica pero muy acertadamente la abogada, escritora y editora Lisa Paddock en su libro Suprem Court for Dummies (2002) que la verdadera petición para que una petición de certiorari progrese no radica en aspectos jurídicos procesales. La clave está en presentar tu caso en el entorno adecuado; y para ello es imprescindible que en tu esquina haya alguien que conozca cómo hacer que los Justices quieran oír tu caso».

34 «At the heart of the top court's transformation into a more professional and businesslike institution is the Court's Chief Executive. The President appoints the Chief executive, to whom responsibility is delegated for the management of the Court's administrative operation. The Constitutional Reform Act 2005 had provided for the Lord Chancellor to appoint the Chief Executive, after consulting with the president.[...] the Chief Executive performs three main functions [...] the Chief Executive must comply with a statutory duty to ensure tan resources are employed to provide an efficient and effective system to support the Court in carrying out its business. [...] The Chief Executive appoints and manages the Court's non judicial staff. Graham GeE, RoBerT Hazell, Kate Malleson and Patrick O’Brien, The Politics of Judicial Independence in the UK's Changing Constitution, Cambridge University Press 2015, p. 203; Resultan ilustrativos los datos que ofrece el artículo de CANCIO FERnÁndez R.C., porque nos resulta curioso que el portal del Poder Judicial, en tiempos de «transparencia» y «regeneración» no dé cuenta detallada de los miembros que integran el Gabinete Técnico. «...En la Corte Suprema de los EEUU cada Juez cuenta con cuatro Law Clerks para cada año judicial [.... ]en el Gabinete Técnico de lo contencioso con 23 miembros como letrados se asiste a 38 magistrados de sala...». 
Generales un proyecto de ley para regular el Estatuto de los Letrados del Gabinete y se remite al artículo 23 de la Ley 38/1988 de 28 de diciembre de Demarcación y Planta Judicial en lo relativo a su retribución.

c) El régimen jurídico del Gabinete ha cambiado, se detalla en la Disposición Transitoria segunda de la reforma de 2015. Los antiguos seis magistrados serán ahora Letrados coordinadores por el tiempo por el que fueron nombrados. Además ahora existirá una nueva modalidad de Letrados que no pertenece a la carrera judicial, estos serán sometidos al régimen estatutario de los letrados de la Administración de Justicia, y ello a la espera de un régimen homogéneo para todo el cuerpo que articulará el futuro estatuto básico.

En definitiva, son muchas las preocupaciones que surgen en torno a este nuevo órgano rediseñado por la reforma de $2015^{35}$. Un órgano con nueva composición y relevantes competencias, pendiente de ulterior régimen de desarrollo pero con una clara subordinación al Presidente del Tribunal Supremo. Un órgano que si crece en competencias debería crecer en «legitimidad». Porque entendemos que los procedimientos de nombramiento (de los Letrados) adquieren relevancia a medida que las competencias a realizar por ellos dejan de ser labores puramente formales o administrativas para convertirse en tareas, en palabras de Santamaría Pastor, que tienen más de «examen de fondo del asunto, tan intenso y exigente como la posterior preparación de la ponencia por parte del Magistrado» ${ }^{36}$. Podríamos anunciar como hace el propio Santamaría que las tareas de «desescombro» por parte de los Letrados del Gabinete quedan sin duda atrás.

Se ve, como clara punta de iceberg, el Gabinete Técnico, órgano relevante del Tribunal Supremo que encara una nueva etapa. La trascendencia de su nuevo papel requiere, a nuestro juicio, un meditado proceso de selección de sus Letrados y, desde luego, la articulación de mecanismos de supervisión y control de sus decisiones.

35 Diario de Sesiones, Congreso de los Diputados, n. ${ }^{\circ} 272$, de 16 de abril de 2015, p. 105, pleno: «... Señor ministro, [...] Su reforma, [...] siempre expresan añoranza del pasado, [...] este proyecto pone de manifiesto una intención clara del Gobierno que, por otra parte, ya es habitual, que no es otra que controlar el Poder Judicial, en este caso a través de los órganos del Consejo General del Poder Judicial. Ya se puso de manifiesto su intención en la Ley Orgánica 4/2013, de 28 de junio, y en este proyecto de ley se pone al descubierto. Como muestra, tres ejemplos. En primer lugar, el Gobierno vuelve a modificar la composición de la comisión permanente del Consejo General del Poder Judicial, [...] Incrementan la comisión permanente del consejo general en dos miembros más. Señor ministro, ¿por qué no lo ha explicado en su intervención? Si en 2013 pusieron seis ¿por qué ahora ocho? ¿A qué obedece este cambio? ¿Qué pretenden con él? ¿Se lo ha solicitado alguien en especial? Hay muchos interrogantes a los que ustedes debieran responder porque, si no dan respuestas, tendremos que aplicar el refrán de piensa mal y acertarás. [...], la nueva regulación del gabinete técnico del Tribunal Supremo lo reconvierten en gabinete del presidente (la cursiva es nuestra), que puede derivar, o acaso sea esa la intención, en un órgano de control de la sala. Muchas intenciones, no sé si inconfesadas e inconfesables, señor ministro. Poca claridad y mucha opacidad...».

36 Santamaría Pastor J.A., op. cit. p. 39. 


\section{REFLEXIONES SOBRE LA PARTE SUMERGIDA ;UN RENOVADO ENFOQUE DE LA INDEPENDENCIA JUDICIAL?}

Consideramos esta parte de nuestro análisis como la más compleja de recorrer. Es la parte del iceberg sumergida y que no se percibe con tanta claridad. Sus contornos son difusos y su sistemática cuasi imposible, de ahí que movidos por el afán de estudio de un tema complejo y clásico tan sólo vayamos a reflexionar en voz alta sobre algunas aproximaciones al mismo. La intención es respetar sus imprecisos contornos y sus atropellados volúmenes, lo que entendemos no resta contundencia a su presencia...

\section{Reflexiones sobre las relaciones entre el Consejo General del Poder Judicial y el Tribunal Supremo}

Según nuestro diseño institucional y su regulación constitucional estamos frente a dos órganos constitucionales distintos. Uno como cúspide del poder judicial, otro como gobierno del mismo. Las relaciones que se proyectan entre estos dos órganos condicionan desde luego el concepto y realidad de la independencia judicial en sus dos proyecciones ya explicadas por la STC 108/1986, de 29 de julio, fundamento jurídico séptimo: «de cada juez o tribunal en el ejercicio de su jurisdicción...»e «independencia en el interior de la organización judicial... así las funciones que obligadamente ha de asumir el Consejo (CGPJ) son aquellas que más pueden servir al Gobierno para intentar influir sobre los tribunales: de un lado, el posible favorecimiento de algunos jueces por medio de nombramientos y ascensos; de otra, las eventuales molestias y perjuicios que podrian sufrir con la inspección y la imposición de sanciones. La finalidad del Consejo es, pues, privar al Gobierno de esas funciones y transferirlas a un órgano autónomo y separado. Es, desde luego, una solución posible en un Estado de Derecho, aunque, conviene recordarlo frente a ciertas afirmaciones de los recurrentes, no es su consecuencia necesaria ni se encuentra, al menos, con relevancia constitucional, en la mayoría de los ordenamientos jurídicos actuales». ¿Es el Consejo un órgano separado y autónomo, de nuestro Tribunal Supremo? ¿Cumple el Consejo el papel para el que fue diseñado? ¿Es necesario...?

Es siempre un buen ejercicio volver sobre los principios $^{37} \ldots$

El informe de la Comisión constituyente de la Constitución gaditana de 1812 introdujo ya la necesidad de un Tribunal Supremo, como centro común en

37 Decía en el primer discurso de toma de posesión, el primer presidente del Tribunal Supremo, Ramón de Posada y Soto en 1812: «...Nosotros los que componemos este Supremo Tribunal tenemos en el artículo 261 de la Constitución determinada la extensión de nuestras facultades. Obligados a no separarnos de la ley no debemos omitir ni vigilias, ni estudios, ni tareas que conduzcan a su mejor aplicación, no corresponderíamos de otra suerte a la confianza que la nación hace de nosotros. Seremos felices si administramos justicia con integridad, si procedemos sin acepción de personas o parcialidad, si nuestros cuidados se extienden a que los subalternos cumplan sus deberes con exactitud, si sentenciamos como la ley sin odio ni pasiones...». 
materia de justicia y que, en un primer momento, inspeccionaría todos los Jueces y tribunales en el ejercicio de sus tareas como administradores de justicia ${ }^{38}$.

La Constitución española en su artículo 123 define el Tribunal Supremo como el órgano superior en todos los órdenes, salvo lo dispuesto en materia de garantías constitucionales. Esta idea básica fue explicada por el Tribunal Constitucional, en su temprana sentencia 62/1990, de 30 de marzo: «...El ámbito que permite caracterizar como "superiores» a estos Tribunales Superiores de Justicia no es sólo un espacio físico que delimita una Comunidad autónoma, sino el espacio normativo peculiar de cada Comunidad, a lo que se ha de agregar que el Tribunal Supremo es configurado por la Constitución como superior en todos los órdenes, caracterización que no tiene un significado bonorifico o puramente jerárquico, sino que se ba de interpretar según la significación tradicional y clásica del Tribunal Supremo como órgano encargado de realizar una labor unificadora en la aplicación del Derecho realizada por los demás órganos jurisdiccionales. Esta labor unificadora se debe extender a todos los ámbitos en que sea posible su efectivo despliegue y, por consiguiente, a todos aquellos casos en los que un órgano, estatal o autonómico aplique Derecho común susceptible de ser unificado...»

Asimismo, el artículo 122.3 de la CE puso a su vez de relieve que el Presidente del Tribunal Supremo, no sólo formaba parte del Consejo General del Poder Judicial, sino que lo "presidiría». Un modelo judicial con un órgano de gobierno independiente que tendría al frente al también presidente del Supremo Tribunal. La misma persona al frente de órganos distintos, la misma persona como gobernador y gobernado, como controlador y controlado, como inspeccionador e inspeccionado.

El artículo 585 de la LOPJ se expresa en tal sentido: «El Presidente del Tribunal Supremo y del Consejo General del Poder Judicial es la primera autoridad judicial de la Nación y ostenta la representación del Poder Judicial y del órgano de gobierno del mismo, correspondiéndole el tratamiento y los honores inherentes a tal condición». La ley añade como requisito ostentar la condición de magistrado del Tribunal Supremo con las condiciones añadidas para ser presidente de Sala o ser jurista de reconocida competencia con más de 25 años en el ejercicio de la profesión. A su vez, una de las causas de cese del Presidente del Tribunal Supremo (art. 588.3 LOPJ) es la decisión por tres quintos del pleno del Consejo estimando incapacidad o incumplimiento grave. Y es requisito que la duración del mandato del Presidente del TS y del CGPJ haya de coincidir con la del mandato del Consejo que lo eligió.

Por su parte el Vicepresidente del Tribunal Supremo es nombrado por el Consejo General del Poder Judicial (art. 560.1.13. ${ }^{\circ}$ LOPJ) y sustituirá al Presidente por ausencia, enfermedad, vacante o cualquier otro motivo justificado. Po-

38 SánChez de la Cuesta SánChez de Ibargüen F., «La sentencia del Tribunal Constitucional de 19 de marzo de 2012, 200 años de independencia judicial y la pervivencia indefinida de las sanciones pendientes de recursos de alzada no resueltos» en Cuadernos de Inspección del Territorio, 2012, pp. 1-3. 
drá desempeñar las funciones que le encomiende el Presidente produciéndose una suerte de «alter ego» muy dudosa en la figura del Vicepresidente ${ }^{39}$.

$Y$, por último, las relaciones entre estos dos órganos también se ciernen en materia de impugnaciones y de «sanciones disciplinarias». Porque tal como se explicó en páginas anteriores, las decisiones de la comisión permanente no se impugnan ante el Pleno sino ante la sala especial de la sala tercera del Supremo (art. 638 LOPJ).

$\mathrm{Y}$ así, el flujo de relaciones en materia disciplinaria es un continuo «efecto boomerang» entre el Consejo y el Supremo. El recién estrenado en 2013 Promotor de la Acción Disciplinaria, es nombrado por el pleno del Consejo pero sólo podrán ser candidatos magistrados del Tribunal Supremo o magistrados con más de 25 años de antigüedad. Y, ¿qué pasa con las decisiones de la Comisión Disciplinaria que se recurran? Y, ¿con las decisiones impugnadas del Promotor de la Acción disciplinaria? Las primeras se recurrirán ante el Pleno del Consejo poniendo fin a la vía administrativa y podrán dar lugar a su recurso ulterior ante la sala tercera del Tribunal Supremo. Y para las desavenencias con el Promotor, será la Comisión permanente quién deberá decidir sobre la decisión o acuerdo de éste, pudiendo ser también recurrida la decisión de la permanente ante la sala tercera del TS (art. 638 LOPJ).

Xíol Ríos ha señalado que las relaciones del Consejo con el Tribunal Supremo son razonablemente fluidas. «...El ejercicio del control por la sala tercera del TS de los actos del Consejo General del Poder Judicial relativos al estatuto judicial se contempla cada vez más, especialmente en el seno de la carrera judicial, como una consecuencia natural del sistema constitucional de control de la actividad administrativa por los Tribunales ${ }^{40}$. El problema a nuestro juicio es entender si estamos, con esa actividad del Consejo, ante un tipo especial de actividad administrativa que, por ejemplo, afecta directamente a los magistrados de la sala tercera y que tal vez debería recibir un régimen distinto

Desde 1789 fecha de la creación del Tribunal Supremo de los Estados Unidos, hasta octubre de 2009 fecha de la configuración del Tribunal Suprema del Reino Unido ${ }^{41}$ tras la Constitutional Reform Act de 2005, hay muchos años de ex-

39 Gerpe Landín M.A., Cabellos Espiérrez A., «La reforma permanente: el Consejo General del poder judicial a la búsqueda de un modelo», Revista Española de Derecho Constitucional, n. ${ }^{\circ}$ 103, enero-abril 2015, p. 33; «...O se dota al CGPJ de un vicepresidente como lo había tenido hasta 2013, que sustituya al presidente o, si no, habría que ubicar la sustitución en algunos de los vocales, pero traer a una persona externa, perteneciente a otro órgano, carece de sentido y altera la composición constitucionalmente prevista del órgano. Que el vicepresidente del TS haya sido elegido por el Pleno del CGPJ y pueda ser cesado por este no quita que, como se ha dicho, sea una persona externa al órgano, que no forma parte de este...»

40 Xíol Ríos J.A., «La posición constitucional del Tribunal Supremo» en El TS en el ordenamiento constitucional, Jornadas en conmemoración del XXV Aniversario de la Constitución de 1978, Madrid 2004, pp. 85 y ss.

41 Masterman R., «A Supreme Court for the United Kingdom: two steps forward, but one step back on judicial independence», Public Law 2004, spring London pp. 48 y ss. «... Despite the declaration that judges who are appointed to the final court of appeal should be judges, not legislators and the overall intent 
periencias de Tribunales Supremos, también el español. Una constante se hace presente en el diseño y evaluación de todos ellos, su relación con los otros poderes públicos estatales. La calidad y buen hacer de estos Tribunales, además de en la observancia de sus competencias, deberá ponderarse a través del contenido de «tales relaciones». Ahora bien, el cuánto y el cómo de las mismas es lo que adquiere dimensiones peculiares/personales en cada modelo de justicia.

\section{Reflexiones sobre el temido contenido político de la independencia judicial y las, queramos o no, «competencias políticas» del Consejo General del Poder Judicial}

Pero, ¿de qué estamos hablando si la lucha de todos estos años ha sido contra la politización de la justicia, si la crítica más feroz a los sucesivos mandatos de nuestros Consejos del Poder judicial, desde que en 1980 iniciara su andadura, se producía por la seducción política de nuestros vocales o del propio Presidente?

¿Y si encontráramos argumentos que demuestran que la independencia judicial se logra también gracias a una buena política de la justicia y no en espacios de asepsia política que terminan haciendo aguas por irreales? La independencia judicial necesita espacios de límites y responsabilidades. Los jueces, los políticos y los funcionarios públicos necesitan trabajar conjuntamente en el diseño y ejercicio de los procesos de selección de jueces, en la articulación de modelo judicial y el correspondiente engranaje de Tribunales. Esto no es otra cosa que la política de la independencia judicial y de la responsabilidad en el ejercicio de la justicia.

Si la «vieja» comprensión de la política de la independencia judicial podríamos calificarla de: opaca, secreta, escondida en infinitos preceptos normativos (como hemos visto en las páginas iniciales al hablar del Gabinete Técnico o de la Comisión permanente...) y, desde luego, peligrosamente interpretable o flexible (en tan sólo tres

of the policy to establish a new Supreme Court to reflect and enhance the independence of the judiciary from both the legislature and the executive, it seems that the government is still prepared for the potential conflict of interests than may result from judges for the new Supreme Court taking part in public inquires. The reasoning behind the removal of the Law Lords from parliament has been, as we have seen, explicitly motivated by the desire to reduce the potential for judicial involvement in matters of party political controversy within Parliament. That the government is clearly prepared that extra-judicial intercourse with matters of political controversy continue outside the legislature betrays the fact than this desire may not be as clear-cut as first thought...»; WHEELER Russell, «Judicial Independence in the United States of America» en SEIBERT-FoHR A. (ed.), Judicial Independence in Transition, Beiträge zum auslämdischen öffentlichen Recht und Völkerrecht, Band 233, Heidelberg 2012; Seibert-Fohr A. (ed.), Judicial Independence in Transition, Beiträge zum auslämdischen öffentlichen Recht und Völkerrecht, Band 233, Heidelberg 2012: «...The United States experience shows that by and large judges can make impartial decisions in an environment of accountability even recognizing occasional lapses. One reason for this judicial independence is a countervailing cultural expectation that judges should in fact decide cases impartially. Another, truth be told, is the relatively low visibility of courts in all but highly controversial cases. If major segments of the population knew more about what courts did, they might be less tolerant of their work...». 
sentencias de la sala de lo contencioso del Tribunal Supremo se pone de relieve el copernicano giro de la jurisprudencia sobre los nombramientos de libre designación, STS 3171/2006 de 29 de mayo: ahora ya sí que habría que motivar los nombramientos de libre designación a pesar de su necesaria discrecionalidad basada en la confianza personal y política; poco después STS 5818/2009, de 19 de octubre: para entender suficientemente motivado el nombramiento de libre designación aparte de los datos puramente formales, deberían referirse criterios de interés general elegidos como prioritarios en el ánimo de decidir el nombramiento, y la STS $3511 / 2013$ de 26 de abril vuelve a apartarse de la discrecionalidad reforzando los criterios objetivos reglados... $)^{42}$ En definitiva una apuesta enconada por negar la presencia de la política de la independencia judicial.

Pero la «nueva» política de la independencia judicial que empieza a articularse debe ser: aceptada, reconocida e identificada, más formal y burocrática, transparente y abierta (vivimos en la época de los innumerables «portales de la transparencia») y propiciadora de espacios interactivos y plurales de jueces, políticos, funcionarios, juristas o académicos en aras de negociaciones y compromisos (recordemos, por ejemplo, la reciente creada JAC Judicial Appointment Commission del Reino Unido para la recomendación de nombramientos judiciales un ejemplo de política de la independencia judicial). En el nuevo espacio de la política de nuestro sistema judicial (en la visión renovada del elemento político) será importante el rol desempeñado por cada «personalidad» (se hablará de Dívar o de Carlos Lesmes...) porque ello permitirá cierta rendición de cuentas personalizada en el desempeño de responsabilidades judiciales una especie de soft accountability de la que tanto ha escrito la doctrina inglesa y sobre la que nuestro legislador se muestra discrepante ${ }^{43}$.

\section{Reflexiones que ponen de relieve la enorme importancia de los procedimientos de selección de nuestros jueces}

El Consejo de Europa señalaba ya en una Recomendación de 1994 que los jueces debían ser elegidos por el propio poder judicial o, en caso de ser elegidos por el «gobierno», en la completa garantía y salvaguarda de que tales procedi-

42 Gil Cremades R., «Un giro histórico: el Tribunal Supremo abandona su doctrina de que en la función pública administrativa no hay que justificar los nombramientos para puestos de libre designación» Revista Vasca de Administración Pública, número especial 99-100 mayo-diciembre, 2014, pp. 1567 y ss.

43 Ovejero Puente A. M., «Accountability judicial y Consejo General del Poder Judicial» en Independencia Judicial y Estado Constitucional. El gobierno judicial, Monografías 988, Tirant lo Blanch, Valencia 2016, pp. 241 y 242; «Otra medida posible sería, reclamar que los miembros del CGPJ motivaran el voto de elección de uno u otro candidato para asumir públicamente la responsabilidad in eligiendo...» Por otra parte observamos la nueva redacción del artículo 564 LOPJ que exime de comparecer ante el Parlamento al Presidente del CGPJ y a sus vocales fuera de la mera exposición del informe anual de actividad del mismo. 
mientos de selección no estarían influenciados por nada distinto de criterios objetivos de cualificación, integridad, capacidad y eficiencia ${ }^{44}$.

Resulta evidente relacionar la independencia judicial de un determinado sistema con los procedimientos de nombramiento y selección de sus jueces. Cuando la relevancia de un órgano por su naturaleza y por sus competencias es clara, adquiere enorme trascendencia, sin margen de duda, el procedimiento de selección de sus miembros. No es baladí que la Constitución española refiera de manera expresa, los procedimientos de selección de los magistrados del Tribunal Constitucional, de los vocales del Consejo General del Poder Judicial o del mismo Presidente del Gobierno.

El Juez debe ser independiente: en el ejercicio de sus funciones, independiente del método y órgano implicado en su selección, de las decisiones que articulan su cambio de destino, de su proceso personal de promoción, de los mecanismos que le sancionan disciplinariamente y de los poderes políticos que deciden las políticas en materia de justicia. La independencia de un modelo judicial concreto debe analizarse en aspectos concretos y, en nuestra opinión, generará frustración su valoración o análisis en abstracto. Vicky C. Jackson explica muy bien esta idea descendiendo al terreno de los hechos y así, pone de relieve dos parámetros irrefutables como medidores rigurosos de la «independencia judicial»: por una parte, la permisividad de las «opiniones discrepantes» o su prohibición dentro de un modelo judicial ${ }^{45}$ y, por otra parte, el modo de selección de sus jueces. Ambos parámetros serán capaces de medir la calidad y madurez de la «independencia judicial».

Pero volviendo a los métodos de selección de jueces, vemos en el ámbito comparado procesos muy variados: Cortes constitucionales con exigencias especiales respecto de los procesos ordinarios para Tribunales ordinarios (arts. 33, 94 y 98 Ley Fundamental de Bonn); modelos de selección homogéneos para todo tipo de órganos judiciales; procesos de selección con un claro componente político o discrecional (magistrados del Tribunal Supremo español,

44 Council of Europe, Recommendation n. ${ }^{\circ}$ (94) 12, sobre Independencia, Eficiencia y papel desempeñado por los Jueces, adoptado por el Consejo de Ministros de 13 de octubre de 1994.

45 Tal reflexión se suscita dentro de una cultura judicial de common law pero, en nuestra opinión, presenta un contenido perfectamente importable a nuestro modelo judicial. VICKY C. JACKsON explica que, las Cortes Constitucionales (modelos de justicia common law) están frecuentemente sometidas a distintos tipos de controles: controles formales y por tanto legalmente predeterminados (procesos de selección y nombramiento, controles jurisdiccionales...) o informales (opiniones académicas, críticas públicas de sus decisiones e incluso controles fruto de los potenciales riesgos de no cumplimiento o evasión de las decisiones judiciales.) Tal vez tales discrepancias o desacuerdos comportan un factor de «legitimación» en el mundo de la ponderación y equilibrio de las decisiones judiciales. La posibilidad de contraste o discrepancia de las decisiones judiciales, si existe «independencia judicial» significa que el cumplimiento de aquéllas nunca debe ser automático y absoluto. ViCKy C. JACKSON, «Judicial Independence: Structure, Context, Attitude» in Judicial Independence in Transition, Band 233, Max-Planck-Institut für ausländisches öffentliches Recht und Völkerrecht, Springer, Heidelberg 2012; pp. 23 y 24. 
art. 599.4 LOPJ) y procesos de naturaleza administrativa ${ }^{46}$, o parlamentaria o en combinación; métodos que requieren mayorías simples, cualificadas o supermayorías; con presencia de los propios jueces en la selección o ausencia absoluta de éstos; a través de Comités de selección que incluyen jueces o asociaciones judiciales, parlamentarios, juristas, profesores de derecho, miembros del gobierno, etc...; o métodos que entrañan un proceso de votación popular como en Estados Unidos ${ }^{47}$, donde el «derecho de los ciudadanos a la elección de sus jueces» resulta un rasgo cultural en su sistema judicial ${ }^{48}$; procesos de selección con mandatos cortos o muy largos (los periodos largos de ejercicio resultan más independientes de las autoridades de selección, mientras que los breves o coincidentes con elecciones o aperturas y cierres de legislaturas entrañan mayores riesgos); con accesibilidad o dificultad en futuras o posibles «reeleciones»...

En definitiva cada procedimiento es un puzzle de múltiples factores que genera sus propios efectos. Pero independientemente de cuál sea el procedimiento diseñado para seleccionar a nuestros jueces, podemos reflejar dos ideas: por un lado, que tal proceso está íntimamente relacionado con el grado de madurez e independencia de un sistema judicial (será desde luego un buen termómetro a tales efectos) pues generará confianza y legitimidad en el sistema judicial y, por otro, que las decisiones subyacentes eligiendo este u otro método de selección son «políticas». Y aquí no sólo nos referimos al proceso inicial de reclutamiento o selección de nuestros jueces sino también y de manera principal a su promoción y selección para futuros destinos o cargos.

46 Graham Gee, Robert Hazell, Kate Malleson and Patrick O’Brien, op. cit., p. 163; «The $\mathrm{JAC}$ is an independent body responsible for identifying candidates for judicial office in courts and tribunals in England and Wales as well as in certain tribunals whose jurisdictions extend to Scotland or Northern Ireland. It manages a long and highly formalized selection process involving advertising, short-listing by tests or paper sifts, interviews and, for some posts, presentations or role-playing. It was created, despite its name, as a recommending body that makes initial selections for judicial office, with the final say whether or not to appoint made by another decision-making authority. However, [...] the JAC effectively functions more akin to an appointing body...» Es verdaderamente interesante analizar el papel que desempeña este órgano creado tras la Constitutional Reform Act de 2005, como dato puede ponerse de relieve que de las aproximadamente 3500 recomendaciones efectuadas por la JAC en el período comprendido entre 2006 y 2013, sólo cinco de ellas fueron rechazadas.

47 Algunos Estados Norteamericanos lo emplean en la selección de jueces de sus Tribunales, el Bélgica o en algunos Cantones Suizos, ver SEIBERT-FoHr A. (ed.), Judicial Independence in Transition, New York and Heidelberg, Springer, 2012, pp. 521 y ss.; 307 y ss.; 403 y ss.

48 Serra Cristóbal R., La selección de jueces en Estados Unidos, Thomson Reuters, 2011; «...Pese a que la elección popular de los jueces es el sistema menos extendido en el mundo, precisamente por considerarse que es el que más connotaciones políticas aporta al cargo de juez, en EEUU sigue siendo el más utilizado. Cerca del $90 \%$ de los jueces estatales tienen que enfrentarse a algún tipo de elección popular en unos comicios competitivos para acceder al cargo. Y aquellos estados que lo han hecho por un sistema basado en los méritos de los candidatos, [...] es el Gobernador el que elige entre una lista que le presenta una Comisión, deberán hacerlo (el someterse a un proceso de elección popular) al finalizar su primer período de mandato para mantenerse en el cargo y ser reelegidos, aunque en este caso se trata de elecciones no competitivas. Es el modo de seguir manteniendo la responsabilidad de los jueces ante el cuerpo electoral...». 
Quizá sea poner puertas al campo sistematizar la gran cantidad de métodos existentes en la selección de jueces además factores culturales, políticos, jurídicos, sociales, económicos o históricos participan activamente. En terminología de Guarnieri y Pederzoli P. ${ }^{49}$ se podrían establecer dos grandes clasificaciones: los sistemas de civil law que siguen un sistema de selección «burocrático» ${ }^{50}$ (Francia, Italia, Portugal o España...) y, los sistemas de common law (Reino Unido, Nueva Zelanda, Canadá, Australia o Estados Unidos...) que diseñan un sistema «profesionalizado» ${ }^{51}$ de selección.

Es cierto que ambos modelos de selección abogan por «limitar» o «restringir» el papel o presencia de las instituciones políticas representativas en los procesos selectivos (Partidos políticos, Sindicatos, Asociaciones, Grupos de presión, Parlamento, etc.) Y a su vez, las principales diferencias en ambos sistemas de selección, según Graham GeE residen en: por un lado, la dimensión política en los sistemas «profesionalizados» está más presente en el proceso inicial de selección $y$, por el contrario, en los sistemas «burocráticos» tal ingrediente político se hace fuerte en la posterior promoción del juez y en los potenciales cargos o destinos a ocupar.

En el modelo judicial español existe una clara diferencia entre el acceso al cargo judicial mediante el sistema de concurso-oposición y la posibilidad de llegar a ser magistrado de un Tribunal Superior de Justicia y no digamos del Tribunal Supremo, así el artículo 299 de la LOPJ señala que la carrera judicial consta de tres categorías: Juez, Magistrado y Magistrado del Supremo.

Otra diferencia importante de los modelos descritos es la creciente dependencia de un órgano de gobierno judicial en los sistemas de civil law («burocráticos») y, una creciente búsqueda de independencia y distanciamiento de los Comités de nombramiento u órganos de selección, en los de common law («profesionalizados»). El creciente poder del Consejo General del Poder Judicial en España, como órgano de gobierno, tal vez respondería a las tendencias comunes de mode-

49 Guarnieri C. and Pederzoli P., The power of Judges: A comparative Study of Courts and Democracy, Oxford University Press 2002, pp. 66 y ss.

50 «...It conceives of the judiciary as part of the national public bureaucracy. Judges are viewed as civil servants, that is to say, as functionaries, with their primary role to apply pre-existing legal rules promulgated by the legislature. Under the model, the traditional assumption is that the judicial function involves important but largely routine work, with the outcome of disputes typically of greater significance to the litigants than the wider community...». Graham Gee, «The Persistent Politics of Judicial Selection: A Comparative Analysis» in SEIBERT-FoHr A., (ed.) Judicial Independence in Transition, New York and Heidelberg, Springer, 2012; pp. 123 y 124.

51 «...the professional model places more stress on judging as a public office to which those who excel at the bar aspire. Judging, especially in the appellate courts, is generally recognized as performing important social and constitutional tasks for example, by enunciating principles that provide certainty to commercial transactions or holding politics actors to account for legal wrongs on legal grounds. [...] the judicial functions has long been recognizes as political, in the sense that the judges exercise discretion when deciding contentious public policy questions under the guise of politically sensitive legal disputes...», Graham GeE, ibídem, pp. 127 y ss. 
los de civil law y ello, desde luego, con todas las prudencias necesarias derivadas de entender que cada modelo judicial estatal está lleno de matices, casi tantos como órganos judiciales.

Nuestros procesos de selección, burocráticos en un primer momento, descansan en el Consejo General del Poder Judicial que es competente según prescripción constitucional de nombramientos, ascensos, inspección y régimen disciplinario. Pero el componente político está presente tras esa etapa inicial haciéndose cada vez más fuerte. Nuestro modelo es profundamente jerárquico y ello condiciona, caprichosamente, la promoción, resultando muy acertada, a nuestro juicio, la pregunta de Itziar Gómez Fernández: ¿ ‘son los jueces que quieren progresar en la carrera judicial realmente independientes? ${ }^{32}$

Tal vez el modelo español de selección de jueces necesita una reflexión en profundidad y un buen ejemplo de tal remodelación se ha sido vivido los últimos diez años en el Reino Unido con el importante paquete de medidas adoptadas tras la Constitutional Reform Act de 2005, que entre otras novedades, articuló un nuevo procedimiento de selección de jueces a través de la creación de la JAC (Judicial Appointment Commission) una comisión independiente con presencia de opciones políticas y con diversas fases burocráticas en aras de identificar la cualificación y méritos de los candidatos, que en palabras de Kate MaLleson: «...The rationale for the establishment of a commission must be that it will guarantee the Independence of the system from inappropiate politicisation, strengthen the quality of the appointments made, enhance the fariness of the selection process, promote diversity in the composition of the judiciary an so rebuild public confidence in the system... ${ }^{53}$. En definitiva podemos decir que la conexión entre la «confianza o credibilidad» de un proceso de selección de jueces y la legitimidad del sistema judicial es muy estrecha.

Por último, debe considerarse al analizar los entresijos de la actual independencia judicial: la responsabilidad del juez en particular y, la del órgano judicial en la administración de justicia además de, la del órgano de gobierno, al gestionar y ejercitar sus competencias.

Pero la independencia judicial que tanto preocupa en general y en particular no puede entenderse de manera absoluta. El juez no puede ser completamente independiente, su actividad no puede desarrollarse de manera autónoma, su proceso de nombramiento y su ulterior promoción están inmersas en diversas rela-

52 Gómez Fernández I., «Nombrar como manifestación del poder del Consejo: discrecionalidad e independencia del juez» en Aguiar de LuQue L., Independencia Judicial y Estado Constitucional. El gobierno judicial, Monografías Tirant 988, Valencia 2016, pp. 96 y 97; «...si fuéramos ingenuos, pensaríamos que los Jueces son independientes, pero no lo somos, ni los jueces y magistrados tampoco, y son bien conscientes de que el acceso a los puestos más altos del escalafón dependen de los nombramientos del Consejo General del poder Judicial, unos nombramientos altamente discrecionales, a pesar de los límites introducidos por el Tribunal Supremo, el Tribunal Constitucional, el legislador y el propio Consejo en el ejercicio de su potestad reglamentaria...».

53 Kate Malleson, «Creating a Judicial Appointment Commission: which model Works best?», Public Law, 2004, spring London, pp. 103 y ss. 
ciones, sus sanciones, su salario y su propia interpretación y aplicación de la ley requieren de un entramado de relaciones e interdependencias. Ahora bien, estas últimas deben ser apropiadas, proporcionadas y respetar el necesario margen de autonomía que legitima al juez y que LóPez GUERRA explicaba como: «...el sometimiento del juez en exclusiva a la ley supone su no sometimiento a cualquier otra voluntad incluida la suya propia...»

La exigencia o requerimiento de «responsabilidades» resulta un concepto difícil de explicar y que ha ido evolucionando desde luego. Probablemente necesario en un Estado de Derecho que inserta el principio de separación de poderes como eje vertebral de nuestra democracia, descansando en un engranaje de frenos y contrapesos. Los últimos veinte años asistimos a la revolución de la teorización de la función de control y de los mecanismos de control y de exigencia de responsabilidades. De la accountability se ha dicho que es un «slippery concept ${ }^{54}$ (concepto resbaladizo), se la ha tildado también de «amorphous concept» ${ }^{55}$, no pretendemos desde luego en estas líneas hacer un estudio en profundidad de una materia tan compleja y de contornos tan poco nítidos. Pero sí coincidimos con opiniones que han puesto de relieve las serias dificultades del modelo español en aras de concretar y llevar a la práctica un cierto control judicial en todas sus variables. Un ejemplo normativo, al que ya nos hemos referido en páginas anteriores, ilustra bien esta crítica (art. 564 LOPJ) que exime de la obligación de comparecencia de nuestros vocales del Consejo ante las Cámaras para dar cuenta de sus actuaciones.

Habrá que reflexionar, como el panorama comparado de otros Estados nos propone, sobre un nuevo diseño de esta necesidad de control judicial y ello en dos grandes planos, distintos y complementarios: soft accountability y hard accountability. No es desde luego lo mismo, la separación de la carrera judicial (como sanción disciplinaria regulada en el art. 599.1.10. ${ }^{\circ}$ LOPJ que se reserva al Pleno del Consejo) que la crítica sufrida por un magistrado en sus argumentos jurídicos a través de varios votos particulares de colegas o a través del malestar social vertido en artículos de prensa... La diferencia entre ambos procedimientos es lo que la doctrina inglesa ha denominado como Sacrifical accountability and explanatory accountability, ambos planos de control son necesarios.

\section{ALGUNAS CONCLUSIONES}

La independencia judicial que siempre ha criticado duramente la «politización de la justicia» debe empezar a aceptar y descubrir que no habrá tal inde-

54 Graham Gee, Robert Hazell, Malleson Kate and Patrick O’Brien, op. cit., p. 17.

55 Le Sueur ANDREw, «Developing mechanisms for judicial accountability in the UK» Legal Studies, volume 4, issue 1-2, March 2004, pp. 73-98. 
pendencia desde la asepsia política, sino con una ponderada, transparente y legítima presencia política. Lejos de una obsoleta y artificial comprensión de la independencia judicial como la radical separación entre jueces y políticos, la verdadera independencia judicial debe entenderse como fruto de la política. Sólo se logrará aquélla a través de una renovada y pública interactuación entre jueces y políticos ${ }^{56}$.

Hemos analizado la reforma de la Ley orgánica del Poder Judicial de octubre de 2015 porque analizando los cambios que propone creemos que se derivan preocupantes efectos.

En primer lugar, la Comisión Permanente se ha convertido en un órgano independiente dentro del Consejo, subordinado a la figura del Presidente y que ha visto crecer su protagonismo y competencias. Queda sin justificación que un órgano colegiado, reducido, de trabajo, cuya vocación es ser más eficiente, sortee su rendición de cuentas ante el Pleno que es quien ostenta la legitimidad de origen y de funcionamiento. Desde 2013 hay dos categorías de vocales, los de la «permanente» y el resto. Y por último, el episodio de «no renovación» vivido por la primera Comisión permanente ejemplifica también tal diagnóstico de órgano presidencialista.

En segundo lugar hemos estudiado que coinciden en la reforma, la nueva casación y la nueva regulación del Gabinete Técnico del Tribunal Supremo. Una coincidencia, no fortuita a nuestro juicio, que transforma el órgano de asesoramiento e información del Tribunal Supremo en un órgano con competencias de fondo en la admisión o inadmisión de los nuevos recursos con interés casacional objetivo. Un órgano creado, dirigido y cesado bajo la estricta vigilancia y supervisión del Presidente del Tribunal Supremo y que adquiere una naturaleza más que técnica.

Las medidas concretas producen efectos concretos y sirven para volver sobre reflexiones clásicas. Constituyen una oportunidad de nuevos enfoques y reformas. La independencia judicial se construye en abstracto y en concreto, con principios teóricos y axiológicos pero también y, sobre todo, mediante el diseño específico de medidas. Los dos planos deben ir de la mano

Nuestro Consejo General del Poder Judicial necesita aceptar que tiene también una naturaleza política. Que desempeña competencias políticas y que así, siendo consciente de ello debe trabajar en espacios heterogéneos y con órganos plurales que integren desde la normalidad esta realidad. Y ello requiere transparencia y pluralismo. Las relaciones que el Consejo ha ido tejiendo todos estos años con el Tribunal Supremo hacen peligrar la franja de conveniente y querida independencia entre estos dos órganos. Ello enturbia la confianza en los procesos de selección de nuestros jueces y en la promoción posterior de sus carreras profesionales en aras de ostentar puestos en la carrera judicial. Independencia, legitimi- 
dad y confianza se requieren en cualquier modelo de selección de jueces. No hablaremos de un mal sistema judicial si tenemos buenos jueces.

$$
* * *
$$

TITLE: New approaches to judicial independence. Two iceberg's Tips in the 2015 reform of the Organic Law of the Judiciary: the Standing Committee of the General Council of the Judiciary and the Technical Office of the Supreme Court

ABSTRACT: This paper analyses two reforms about Organic Law of Judiciary which have been made in October 2015: the Permanent Commission as part of Council body that it has seen increasing its competences and it works under careful supervision of the President of the General Council of the Judiciary. It has suffered an augmentation of members on its composition and it has got more relevance as important voice in the General Council and, on the other hand, the Technical office of the Supreme Court, which has been redesigned with new competences working under Instructions of President. And all these changes are been implemented at the same time that it has been adopted the new cassation appeal. Both reforms as iceberg's tips are performing important reflections about classical principles for example: different manners to understand the judicial independence, the political element within judicial independence, the relevance of appointment judicial processes and of course the accountability discourse as essential part within the judicial independence.

Resumen: Este trabajo estudia dos reformas concretas de la Ley orgánica del Poder Judicial que se producen en octubre de 2015: la Comisión Permanente, como órgano del Consejo que ve incrementado su número de vocales, sus competencias y que situado bajo la dirección del Presidente del Consejo ba ido creciendo en relevancia; y el Gabinete Técnico del Tribunal Supremo, que se regula también como órgano al servicio del Tribunal pero bajo la obediencia y dirección del Presidente. Un órgano que asume unas competencias muy importantes en un momento en el que se reforma la vieja casación pasando a ser un recurso determinado por el «interés casacional objetivo». Estos dos cambios, como puntas de iceberg, son el aviso de nuevos enfoques sobre planteamientos clásicos acerca de la independencia judicial tales como: las relaciones existentes entre el Consejo General del Poder judicial y el Tribunal Supremo, la presencia del elemento político en el corazón de la independencia judicial, la enorme relevancia de un proceso de selección de nuestros jueces justo, plural y confiable y la necesidad de articular mecanismos de responsabilidad judicial institucional e individual.

KEY wORDS: Judicial independence, judicial appointment processes, political element within judiciary, judicial accountability.

Palabras clave: Independencia judicial, procesos de selección de jueces, lo político en el sistema judicial, responsabilidad judicial.

FECHA DE RECEPCIÓN: 20.05.2016

FECHA DE ACEPTACIÓN: 27.07.2016

UNED. Teoría y Realidad Constitucional, núm. 38, 2016, pp. 375-408 